OPEN ACCESS

Edited by:

Haiwei Xu,

Army Medical University, China

Reviewed by:

Sina Naserian,

Hôpital Paul Brousse, France

Philippe Bourin,

Independent Researcher, Toulouse,

France

${ }^{*}$ Correspondence:

José Carlos Rivera

jc.rivera@umontreal.ca

Sylvain Chemtob

sylvain.chemtob@umontreal.ca

Specialty section

This article was submitted to

Stem Cell Research,

a section of the journal

Frontiers in Cell and Developmental

Biology

Received: 18 November 2020

Accepted: 04 January 2021

Published: 21 January 2021

Citation:

Noueihed B, Rivera JC

Dabouz R, Abram P, Omri S, Lahaie I and Chemtob S (2021) Mesenchymal

Stromal Cells Promote Retinal Vascular Repair by Modulating Sema3E and IL-17A in a Model

of Ischemic Retinopathy.

Front. Cell Dev. Biol. 9:630645. doi: 10.3389/fcell.2021.630645

\section{Mesenchymal Stromal Cells Promote Retinal Vascular Repair by Modulating Sema3E and IL-17A in a Model of Ischemic Retinopathy}

\author{
Baraa Noueihed 1,2, José Carlos Rivera1,3*, Rabah Dabouz¹, Pénélope Abram¹, \\ Samy Omri ${ }^{1}$, Isabelle Lahaie ${ }^{1}$ and Sylvain Chemtob ${ }^{1,2,3 *}$
}

${ }^{1}$ Department of Ophthalmology, Maisonneuve-Rosemont Hospital Research Center, University of Montréal, Montréal, QC, Canada, ${ }^{2}$ Department of Pharmacology and Therapeutics, McGill University, Montréal, QC, Canada, ${ }^{3}$ Departments of Pediatrics, Ophthalmology and Pharmacology, Centre Hospitalier Universitaire Sainte-Justine Research Center, Montréal, QC, Canada

Ischemic retinopathies (IRs), such as retinopathy of prematurity and diabetic retinopathy, are characterized by an initial phase of microvascular degeneration that results in retinal ischemia, followed by exaggerated pathologic neovascularization (NV). Mesenchymal stromal cells (MSCs) have potent pro-angiogenic and anti-inflammatory properties associated with tissue repair and regeneration, and in this regard exert protection to neurons in ischemic and degenerative conditions; however, the exact mechanisms underlying these functions remain largely unknown. Class III Semaphorins (A-G) are particularly implicated in regulating neural blood supply (as well as neurogenesis) by suppressing angiogenesis and affecting myeloid cell function; this is the case for distinct neuropillin-activating Sema3A as well as PlexinD1-activating Sema3E; but during IR the former Sema3A increases while Sema3E decreases. We investigated whether retinal vascular repair actions of MSCs are exerted by normalizing Semaphorin and downstream cytokines in IR. Intravitreal administration of MSCs or their secretome (MSCs-conditioned media [MSCs-CM]) significantly curtailed vasoobliteration as well as aberrant preretinal NV in a model of oxygen-induced retinopathy (OIR). The vascular repair effects of MSCs-CM in the ischemic retina were associated with restored levels of Sema3E. Vascular benefits of MSCs-CM were reversed by anti-Sema3E; while intravitreal injection of anti-angiogenic recombinant Sema3E (rSema3E) in OIRsubjected mice reproduced effects of MSCs-CM by inhibiting as expected preretinal NV but also by decreasing vasoobliteration. To explain these opposing vascular effects of Sema3E we found in OIR high retinal levels, respectively, of the pro- and anti-angiogenic

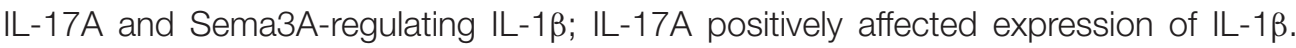
rSema3E decreased concentrations of these myeloid cell-derived pro-inflammatory cytokines in vitro and in vivo. Importantly, IL-17A suppression by MSCs-CM was 
abrogated by anti-Sema3E neutralizing antibody. Collectively, our findings provide novel evidence by which MSCs inhibit aberrant NV and diminish vasoobliteration (promoting revascularization) in retinopathy by restoring (at least in part) neuronal Sema3E levels that reduce pathological levels of $\mathrm{IL}-17 \mathrm{~A}$ (and in turn other proinflammatory factors) in myeloid cells. The ability of MSCs to generate a microenvironment permissive for vascular regeneration by controlling the production of neuronal factors involved in immunomodulatory activities is a promising opportunity for stem cell therapy in ocular degenerative diseases.

Keywords: interleukin-17A, semaphorin 3E, ischemic retinopathies, vascular regeneration, mesenchymal stem cells

\section{INTRODUCTION}

Ischemic retinopathies (IRs), such as retinopathy of prematurity (ROP) and diabetic retinopathy (DR), are leading causes of severe visual impairment and blindness in children and the working population, respectively, (Mora et al., 2018; Sabanayagam et al., 2019). These ocular diseases are characterized by retinal vasculature impairment that originates from local hypoxia, which triggers an exaggerated and uncontrollable pathological neovascularization (NV). Several molecules have been described to play an important role in pathological ocular $\mathrm{NV}$, of which vascular endothelial growth factor (VEGF) is most reported. Anti-VEGF therapy has proven effective in reducing $\mathrm{NV}$ areas and improving the vision of some patients with retinopathy. However, anti-VEGF agents do not facilitate revascularization of the retina, resulting in undesired outcome (Ghasemi Falavarjani and Nguyen, 2013; Bracha et al., 2018; Low et al., 2019). Lately, adult stem-cell based therapies have emerged as alternative therapeutic avenues to treat IRs (Dorrell et al., 2004; Sivan et al., 2016; Bertelli et al., 2020). In particular, Mesenchymal Stem/Stromal Cells (MSCs) are a most promising modality for the treatment of ocular diseases (Joe and Gregory-Evans, 2010; Ding et al., 2017) because of their remarkable immunomodulatory and angiogenic capacities (Singer and Caplan, 2011; Nassiri and Rahbarghazi, 2013; Tao et al., 2016; Weiss and Dahlke, 2019); correspondingly, MSCs exert protective functions on brain and retinal neurons (Harrell et al., 2019; Zhang et al., 2020). These adult multipotent stromal cells exert their reparative effects either by cell differentiation to replace damaged cells or through paracrine fashion via their secretome (Konala et al., 2016; Jaimes et al., 2017; Mead and Tomarev, 2017; Harrell et al., 2018); however, since MSCs have low engraftment efficiency and poor differentiation at the site of injury, an action involving secretion of bioactive molecules seems to be favored in their modulation of tissue microenvironment (Tran and Damaser, 2015; Harrell et al., 2019). But, the exact mechanism of MSC functions on vascular repair is likely diverse and remains largely unclear.

We previously highlighted the importance of neuron-derived signaling molecules on retinal endothelial cell function (Joyal et al., 2011; Rivera et al., 2013), particularly as it applies to guidance molecules of the class III semaphorins family (Sema3ASema3G), which are derived from retinal ganglion cells (RGCs), and are key regulators of developmental and pathological angiogenesis in the retina (Fukushima et al., 2011; Joyal et al., 2011; Kim et al., 2011; Buehler et al., 2013; Yang et al., 2015; Ochsenbein et al., 2016). Semaphorins can in turn affect the activity of myeloid cells (Ito et al., 2012; Neufeld et al., 2016). Most Sema3s (as clearly described for Sema3A-E) exert anti-angiogenic functions (Toledano et al., 2019). Interestingly, Sema3E (a key axon repulsive protein) is implicated in immune cell regulation and vascular growth and remodeling (Oh and Gu, 2013; Shimizu et al., 2013; Wanschel et al., 2013; Movassagh et al., 2017b; Alamri et al., 2018; Kermarrec et al., 2019), as it selectively inhibits disoriented outgrowth of extraretinal vessels and restores the normal vasculature in ischemic retina (Fukushima et al., 2011). Sema3E exerts its actions on endothelial cells via a singlepass transmembrane receptor, PlexinD1 (Kruger et al., 2005). During retinal development as well as in ischemic retinopathy, PlexinD1 is located on endothelial cells exclusively at the front of actively sprouting blood vessels, while its ligand Sema3E is generated by RGCs (Kim et al., 2011; Sun et al., 2017). Sema3EPlexinD1 complex trigger an antiangiogenic signaling pathway that suppresses endothelial cell motility by inducing cytoskeletal rearrangements that cause filopodial retraction (Sakurai et al., 2010; Fukushima et al., 2011), and inhibits endothelial cell growth and tube formation (Kim et al., 2011). Semaphorins can also modulate angiogenesis (and tumor progression) by regulating immune cell function, as documented for Sema3A and Sema3E (Sierra et al., 2008; Movassagh et al., 2019). Conversely, decreased expression of Sema3E aggravates inflammation and exacerbates disease severity by upregulating the release of pro-inflammatory cytokines, notably of interleukin-17A (IL-17A) (Movassagh et al., 2017b; Kermarrec et al., 2019), which in turn can affect NV (Talia et al., 2016; Li and Zhou, 2019); concordantly, IL-17A plasma levels are high in DR and ROP (Sood et al., 2010; Semeran et al., 2013). Hence, Semaphorins seem to represent an important class of factors that exert important vascular, immunomodulatory and neuronal functions. However, the role of Sema3E and its interaction with IL-17A as it applies to MSC actions in IRs, is not known.

Using an OIR mouse model, we showed that MSCs modulate the microenvironment of ischemic retinas enabling vascular regeneration and thus diminishing vasoobliteration and inhibiting aberrant pre-retinal NV. MSCs secretome suppresses the expression of Sema3A and intriguingly markedly stimulates 
that of Sema3E, both of which arise from the ganglion cells in retina of animals subjected to OIR. Upon exploring the role of Sema3E it has been found that this Semaphorin not only inhibits $\mathrm{NV}$ by acting directly on vascular endothelium (Toledano et al., 2019) but also acts on myeloid cells by repressing pro-angiogenic IL-17A expression (Li and Zhou, 2019), that negatively impacts production of primary pro-inflammatory cytokines IL-1 $\beta$, IL-6, and TNF- $\alpha$ in these cells; these cytokines are known to upregulate expression of the anti-angiogenic Sema3A and conversely its suppression enhances retinal revascularization of vasoobliterated areas (Joyal et al., 2011; Rivera et al., 2013). Thus, in presence of MSCs, we hereby find that Sema3E mediates to a significant extent the vascular benefits incurred by MSCs secretome, and assists Sema3A to performing opposing functions, specifically accelerating revascularization and diminishing aberrant $\mathrm{NV}$, by controlling inflammation. Collectively, we highlight some evidence by which MSCs secretome regulates the interplay between neurons and immune cells to facilitate healthy revascularization and diminish abnormal $\mathrm{NV}$ in ischemic retina.

\section{MATERIALS AND METHODS}

\section{Animals}

Adult C57BL6/J mice were purchased from Jackson Laboratories. Adoptive lactating CD-1 females were purchased from Charles River to tend to C57BL6/J pups. All experiments adhered to the Association for Research in Vision and Ophthalmology (ARVO) statement regarding use of animals in ophthalmic and vision research and were approved by the Animal Care Committee of Maisonneuve-Rosemont Hospital in accordance with guidelines established by the Canadian Council on Animal Care.

\section{Isolation and Characterization of Mesenchymal Stem/Stromal Cells From Compact Bone}

MSCs characterized by their potential therapeutic properties, easy isolation, wide expansion in vitro, and their abundance in compact bone of many species (Adhikari et al., 2018; Yusop et al., 2018) were isolated from the compact bone of mice as previously outlined (Zhu et al., 2010). Long bones of adult C57BL6/J mice (6-8 weeks) were removed and thoroughly cleaned from any connective tissue. Using a $23 \mathrm{G}$ needle, the bone marrow was flushed out with PBS and saved for subsequent isolation of bone-marrow-derived macrophages (BMDM). Bones were gently crushed and digested with $(2.5 \mathrm{mg} / \mathrm{ml})$ collagenase (Sigma) and 5\% TrypLE Express (Gibco) for $1 \mathrm{~h}$ at $37^{\circ} \mathrm{C}$. Cell suspension was discarded, and bone fragments were cultivated in aMEM (Gibco) supplemented with 20\% Mesenchymal-tested FBS (Wisent) and 1\% penicillin/streptomycin (Corning) at hypoxia $\left(5 \% \mathrm{O}_{2}\right)$ allowing the migration of MSCs out of the compact bone. MSCs were enriched at P2 by negative selection using EasySep Mouse Mesenchymal Progenitor Enrichment Kit (Stem Cell Technologies) to deplete non-mesenchymal lineages. At $80 \%$ confluency, the media was changed to basal $\alpha M E M$. The supernatant, referred herein as conditioned media
(MSCs-CM), was collected $24 \mathrm{~h}$ later, centrifuged, filtered through $0.22 \mu \mathrm{m}$ filter (Millipore), and concentrated 10 times using a $10 \mathrm{~K}$ molecular weight cut off centrifugal filter (Millipore). MSCs-CM was collected between passages 3 and 5. MSCs were characterized based on the minimal criteria put forth by the International Society of Cellular Therapy (Dominici et al., 2006). Immunophenotyping of MSCs was performed by flow cytometry analysis using monoclonal conjugated antibodies against putative MSC surface markers FITC antimouse CD90.2 (eBioscience), PE/Cy7 anti-mouse CD105 (BioLegend), PE anti-mouse CD73 (BioLegend), and against cell lineage markers FITC anti-mouse CD11b (eBioscience) and PE anti-mouse CD34 (BioLegend). FACS was performed on BD LSRFortessa X-20 and data was analyzed using FlowJo software. Compact bone derived-MSCs highly expressed the classical stem cells surface makers CD90.2 ( $\geq 97 \%)$, CD73 $(\geq 94 \%)$, and CD105 $(\geq 95 \%)$ previously characterized in C57BL6/J mice (Caroti et al., 2017) and were negative for hematopoietic and myeloid markers including CD11b $(\leq 1 \%)$ and CD34 $(\leq 0.3 \%)$ (Supplementary Figures 1A,B). MSCs were also differentiated in adipocytes or osteocytes following the instructions described in the mouse Mesenchymal Stem Cell Functional Identification Kit (RnD systems). MSCs' adipogenic and osteogenic potential was confirmed by immunostaining against fatty acid binding protein 4 (FABP4) and osteopontin, respectively, (Supplementary Figure 1C).

\section{Isolation and Stimulation of Bone-Marrow Derived Macrophages}

Bone marrow from tibia and femur of adult mice were flushed with PBS and gently dissociated with 23G needle. The cell suspension was filtered through $70 \mu \mathrm{m}$ strainer and centrifuge at $4^{\circ} \mathrm{C}, 500 \times g$ for $10 \mathrm{~min}$. Cell pellet was resuspended in DMEM containing $10 \% \mathrm{FBS}$ and $20 \mathrm{ng} / \mathrm{ml}$ monocyte colony stimulating factor (M-CSF; PeproTech) to differentiate monocytes into macrophages and seeded in six-well plates. On days 3 and 5 , half of the differentiation media was changed. By day 7 , mature macrophages have formed and attached to the plate. Bone-marrow derived macrophages (BMDM) then were preexposed to hypoxia for $24 \mathrm{~h}$ to assess IL-17A expression levels. Subsequently, BMDM were treated with vehicle, MSCsCM, HypRGC-CM, HypRGC-MSCs-CM, and HypRGC-MSCs in presence of a monoclonal Sema3E antibody $(15 \mu \mathrm{g} / \mathrm{ml}$; R\&D Systems), recombinant mouse Sema3E ( $5 \mathrm{ng} / \mathrm{ml})$, or recombinant mouse IL-17A (100 ng/ml) proteins for another $24 \mathrm{~h}$. RNA was isolated using RNA isolation kit (Qiagen), whereas protein was collected in commercial RIPA buffer (Cell Signaling Technology).

\section{Oxygen-Induced Retinopathy Model}

The OIR model has been well established and standardized to mimic the vascular dysfunction observed in ROP (Smith et al., 1994; Stahl et al., 2010). Postnatal day 7 (P7) C57BL6/J pups were placed with an adoptive lactating CD-1 female in a hyperoxic environment set to $75 \% \mathrm{O}_{2}$ (OxyCycler A820CV; BioSpherix, Ltd., Redfield, NY, United States) until P12 to trigger vaso-obliteration (VO). Then, the animals were returned to 
room air where by hypoxia-driven NV develops at P14 and reaches its peak at P17. Pups at P17 were anesthetized in 3\% isoflurane with oxygen and sacrificed by decapitation. Eyes were enucleated and fixed in $4 \%$ paraformaldehyde for $1 \mathrm{~h}$ at room temperature. Retinas were dissected and stained overnight at $4{ }^{\circ} \mathrm{C}$ with fluorescein labeled GSL I, Isolectin B4 (Vector Labs, 1:100) in PBS containing $1 \mathrm{mM} \mathrm{CaCl}$. Lectin-stained retinas were whole-mounted onto Superfrost/Plus microscope slides (Fisher Scientific) with the photoreceptor side down and embedded in Fluoro-gel (Electron Microscopy Sciences). Multiple 10× images of each whole-mounted retina were taken using the MosiaX option built in Zeiss AxioObserver.Z1 and then merged into a single file using the in the AxioVision 4.6.5 software (Zeiss). Quantification of VO and NV was determined at P17 using SWIFT_NV as described previously (Stahl et al., 2009).

\section{Stimulation of RGC-5}

RGC-5 cells were cultured in DMEM (Invitrogen) supplemented with 10\% FBS (Cell Applications) and 1\% penicillin/streptomycin (Cell Applications) either in normoxia or hypoxia $\left(5 \% \mathrm{O}_{2}\right)$ and treated with MSCs-CM for $48 \mathrm{~h}$ to determine Sema3E mRNA levels. Normoxic and hypoxic RGC-5 cells were stimulated with recombinant IL-17A in a dose-dependent manner for $24 \mathrm{~h}$. RNA was collected in Ribozol (Amersco), whereas protein was collected in commercial RIPA buffer (Cell Signaling Technology).

\section{Immunohistochemistry}

Eyes of P17 C57BL6/J pups exposed to normoxia or OIR were enucleated, fixed in $4 \%$ paraformaldehyde for $1 \mathrm{~h}$ at room temperature, and saturated overnight at $4^{\circ} \mathrm{C}$ in a $30 \%$ sucrose solution prior to embedding in OCT compound (TissueTek $^{\circledR}$ ). Sagittal cross-sections of $10 \mu \mathrm{m}$ was sectioned using a Cryostat (Leica) and permeabilized for $1 \mathrm{~h}$ at room temperature. Immunostaining against Sema3E (R\&D Systems; 1:100), NeuN (EMD Millipore; 1:100), F4/80 (Abcam; 1:100), or IL-17A (Abcam; 1:200) overnight at $4^{\circ} \mathrm{C}$, followed by fluorochrome-conjugated secondary antibody (goat anti-mouse IgG Alexa Fluor 488 and goat anti-rabbit IgG Alexa Fluor 594; Invitrogen) for localization studies according to manufacturers' recommendations. Nuclei were stained with DAPI (Invitrogen; 1:5000). Cross-sections were visualized using $30 \times$ objectives with an IX81 confocal microscope (Olympus), and images were obtained with Fluoview 3.1 software (Olympus).

\section{Retinal Whole-Mounts}

Mice eyes were collected and processed for retinal flat-mounts as previous published studies (Sitaras et al., 2015; Rivera et al., 2017b). Briefly, eyes were fixed in $4 \%$ paraformaldehyde for $1 \mathrm{~h}$ and then, retinas were isolated and incubated overnight at $4^{\circ} \mathrm{C}$ in a solution containing $1 \%$ Triton X-100-1 mM $\mathrm{CaCl}_{2} /$ phosphate-buffered saline (PBS) and TRITC-conjugated lectin endothelial cell marker Bandeiraea simplicifolia (1:100; Sigma-Aldrich, St. Louis, MO, United States). Retinas were mounted and photographed under a Zeiss AxiObserver Z1 motorized inverted microscope (Zeiss, Canada) at $10 \times$. Vasoobliterated areas were assessed as the retinal area devoid of vasculature over the total retinal area by using Adode Photoshop
CS5 (Connor et al., 2009). NV was analyzed using the SWIFT-NV method (Stahl et al., 2009) which was developed to quantify all the pixels represented by neovascular tufts and clusters, but not normal vessels in lectin-stained retinal whole mounts.

\section{Intravitreal Injections}

P12 mice pups were anesthetized in 3\% isoflurane with oxygen and injected intravitreally with $2 \mu \mathrm{l}$ of $\mathrm{CM}$, whereas basal $\alpha \mathrm{MEM}$ (vehicle) was injected in the contralateral eye as control using a Hamilton syringe equipped with 50 -gage glass capillary. $2 \mu \mathrm{l}$ of mouse recombinant Sema3E Fc Chimera (20 ng/ $\mu \mathrm{l}$; R\&D systems) or PBS were administered into vitreous cavity of P12 OIR pups. To assess the effect of blocking IL-17A on the retinal vascularization, $2 \mu \mathrm{l}$ of $5 \mu \mathrm{g} / \mu \mathrm{l}$ neutralizing monoclonal IL17A antibody (Clone 17F3, BioXCell) or of $5 \mu \mathrm{g} / \mu \mathrm{l}$ mouse IgG1 isotype control monoclonal antibody (Clone MOPC-21, BioXCell) was intravitreally injected. To reverse the benefits of Sema3E induced by MSCs-CM administration during OIR, the eyes were injected at P12 and P14 with $2 \mu$ l of blocking Sema3E (5 $\mu \mathrm{g} / \mu \mathrm{l})$ antibody (AF3239, R\&D Systems). To assess the dose-response of MSCs on vasoobliteration, 50,000, 100,000, and 200, 000 cells from passages 3-5 were intravitreally injected in a volume of $2 \mu \mathrm{l}$. Retinal vasculature was analyzed in wholemounts at P17.

\section{Reverse-Transcription PCR and Quantitative Real-Time PCR}

Freshly dissected retinas (2 retinas pooled per $n$ ) were placed immediately in RiboZol (Amresco) and homogenized using Precellys 24 homogenizer. Cultured cells were scrapped using RiboZol (Amresco). RNA was extracted following manufacturer's instructions and then treated with DNase I (Sigma) to remove genomic DNA. $1 \mu \mathrm{g}$ of RNA was reverse transcribed into cDNA using iScript RT Supermix (Biorad) as described by manufacturer's instructions. cDNA was analyzed by Quantitative real-time PCR using iTaq ${ }^{\mathrm{TM}}$ Universal SYBR $^{\circledR}$ Green Supermix (BioRad) with primers targeting mouse Sema3E (Fwd 5'TCTGCAACCCATCCATTCTGAG-3' and Rev 5' -ACCACAAG AGGGAAGCACAGAC-3'), mouse IL-1 $\beta$ (Fwd $5^{\prime}$-CTGGTAC ATCAGCACCTCACA- $3^{\prime}$ and Rev $5^{\prime}$-GAGCTCCTTAAC ATGCCCTG-3'), mouse IL6 (Fwd 5' -ACAGAAGGAGTGGCTA AGGA-3' and Rev 5'-AGGCATAACGCACTAGGTTT-3'), mouse TNF- $\alpha$ (Fwd 5'-GCCTCTTCTCATTCCTGCTTG- $3^{\prime}$ and Rev 5'-CTGATGAGAGGGAGGCCATT-3'), mouse IL-17A (Fwd 5'-CACCGCAATGAAGACCCTGA-3' and Rev 5' $5^{\prime}$-TTCCC TCCGCATTGACACAG-3'), mouse Ror $\gamma$ (Fwd 5'-CCACT ACGGGGTTATCACCTG- $3^{\prime}$ and Rev 5'-TGCAGGAGTAG GCCACATTAC-3'), mouse PlexinD1 (Fwd 5'-TTCCATT TGGTGCTACCTACG- $3^{\prime}$ and Rev 5'-CAATACTTTCTTGC GGTGGC-3'), mouse Sema3A (Fwd 5'-GGGGAACCAGATGA CAGAGA-3' and Rev 5'-GCTCCTGCTCCGTAGCCTGC-3'), mouse VEGF (Fwd 5'-TCGGCGTTGCTTTCGGTCCC-3' and Rev 5'-GCCCTGAGTCAAGAGGACAG-3'), mouse IL-4 (Fwd 5'-CCATATCCACGGATGCGACA-3' and Rev 5'-CG TTGCTGTGAGGACGTTTG-3'), mouse IL-10 (Fwd 5'-GC TCTTACTGACTGGCATGA-3' and Rev 5'-AGAAAGTCTTC 
ACCTGGCTG-3'). Primers were designed by NCBI PrimerBLAST software and synthesized by Alpha DNA (Montreal). Quantitative gene expression analysis was evaluated using ABI 7,500 Real-Time PCR system (Applied Biosystems) and normalized to QuantumRNA ${ }^{\mathrm{TM}} 18 \mathrm{~S}$ universal primer (Invitrogen) using $\Delta \Delta \mathrm{CT}$ method.

\section{Western Blot}

Cultured cells were washed with ice-cold PBS, collected in RIPA lysis buffer (Cell Signaling Technology) and centrifuged to eliminate cell debris. $50 \mu \mathrm{g}$ of cell lysate was loaded on SDS-PAGE gel. After blocking, membranes were blotted against mouse IL17A (Abcam), IL- $\beta$ (Abcam), IL-6 (Abcam), TNF- $\alpha$ (Abcam), Sema3E (Abcam), and $\beta$-actin (Santa Cruz Biotechnology). After washing, membranes were incubated with horseradish peroxidase-conjugated (HRP) anti-mouse or HRP anti-goat or -rabbit secondary antibodies (Millipore). Membranes were imaged with LAS-3,000 imager. Protein band intensities were assessed using densitometry plugins in ImageJ and expressed as a ratio between corresponding protein and $\beta$-actin.

\section{Choroidal Sprouting Assay}

Choroidal explants were prepared from adult C57BL6/J mice as previously described (Shao et al., 2013). Briefly, eyes were rapidly enucleated and dissected to remove the cornea, lens and retina. The choroid/RPE complex was cut into approximately $1 \mathrm{~mm} \times 1 \mathrm{~mm}$ sections and embedded in growth-factor reduced Matrigel in 24-well plates. The choroidal explants are cultured in EBM-2 medium (Lonza, Cat. CC-3156) supplemented with endothelium growth medium (EGM) kit (Lonza, Cat. CC-4147) at $37^{\circ} \mathrm{C}$ in $5 \% \mathrm{CO}_{2}$ for 3 days. On day 4 , the media was changed to vehicle or recombinant mouse IL-17A $(200 \mathrm{ng} / \mathrm{ml})$ in absence or presence of recombinant mouse Sema3E $(5 \mathrm{ng} / \mathrm{ml})$, for another $24 \mathrm{~h}$. Phase-contrast photos of individual explants were taken with ZEISS AxioOberver microscope before and 24-h after treatment. The microvascular sprouting area was measured using Image $J$ software version $1.50 \mathrm{i}$ (National Institutes of Health, United States).

\section{Flow Cytometry and Cell Sorting}

Freshly dissected retinas from treated-OIR pups were pooled (2 retinas per treatment per $\mathrm{n}$ ) and digested in HBSS solution containing $750 \mathrm{U} / \mathrm{ml}$ DNase I (Sigma-Aldrich) and $1 \mathrm{mg} / \mathrm{ml}$ collagenase $\mathrm{D}$ (Roche) for $20 \mathrm{~min}$ at $37^{\circ} \mathrm{C}$ with gentle shaking. Homogenized retinas were then filtered through $70 \mu \mathrm{m}$ cell strainer and supplemented with fluorescent activated cell sorting (FACS) buffer (PBS with 3\% FBS) to quench enzyme activity. Cell suspensions were incubated with LEAF purified anti-mouse $\mathrm{CD} 16 / 32$ (Biolegend) for $10 \mathrm{~min}$ at $4^{\circ} \mathrm{C}$ to block $\mathrm{Fc}$ receptors, followed by $30 \mathrm{~min}$ incubation at $4^{\circ} \mathrm{C}$ of the following antibodies: FITC anti-mouse CD11b (eBioscience) and APC anti-mouse F4/80 (BioLegend). Dead cells were excluded using 7-AAD viability staining solution (BioLegend). FACS was performed on BD LSRFortessa X-20 and data was analyzed using FlowJo software. Myeloid cells $\left(\mathrm{CD} 11 \mathrm{~b}^{+} \mathrm{F} 4 / 80^{+}\right)$were sorted by BD FACSARIA III.

\section{Statistical Analysis}

Results are presented as mean \pm SEM for all studies. Oneway or two-way analysis of variance with significance $\alpha=0.05$ or higher were used for processing data. Bonferroni post hoc analysis was used for calculating significance between groups. Two-tailed student $t$-tests were used to test for significance between two means.

\section{RESULTS}

\section{MSCs Promote Normalization of Ischemic Retinal Vasculature in a Paracrine Fashion}

MSCs were intravitreally injected in OIR animals at the beginning of NV phase on postnatal day 12 (P12). At P17, retinas were isolated to evaluate the degree of vaso-obliteration (VO) and consequential pathological NV (Figures 1A-C). Intravitreally administered MSCs [50,000 cells; similar regenerative efficacy to higher cell concentrations (Supplementary Figure 2A)] significantly reduced the extent of $\mathrm{VO}$, thus enhancing revascularization, and consequently diminished pathological $\mathrm{NV}$, compared to naïve media-treated retinas (Figures 1A-C). Although MSCs were effective, occasionally some cells remained clustered at the injection site, while conditioned medium derived from the same number of MSCs (MSCs-CM) reproduced effects of MSCs on retinal angiogenesis and no drawbacks were detected (Figures 2A-C).

\section{MSCs-Secretome Modulates Retinal Expression of Factors That Affect Retinal Vascular Architectural Network in OIR}

A gene expression array of growth (angiogenic), inflammatory and guidance/apoptotic factors (Figure 3A) performed at P17 after OIR revealed in retinas of MSCs-CM-treated animals (at P12) a marked increase in VEGF, a decrease in pro-inflammatory cytokines IL-1 $\beta$ and IL-17A, as well as, an increase in antiinflammatory IL-10 in comparison to vehicle-treated. These MSCs-CM-induced changes in OIR were associated with a considerable suppression of Sema3A and a notable (threefold) augmentation of Sema3E which is nearly undetected in untreated OIR retinas at P17 (Figure 3B), consistent with previous reports (Fukushima et al., 2011). The MSCs-CMinduced increase in Sema3E in OIR at P17 was confirmed by RT-PCR (Supplementary Figure 2B), as well as by immunohistochemistry where, as expected (Fukushima et al., 2011; Sharma et al., 2014; Sun et al., 2017), Sema3E was detected in the ganglion cell layer (Figure 3C).

In an attempt to mimic in vitro the in vivo conditions related to OIR, we confirmed that MSCs-CM triggered induction of Sema3E gene expression and protein in hypoxic (5\% $\left.\mathrm{O}_{2}\right)$ RGC (Figure 4A), but not in normoxic $\left(21 \% \mathrm{O}_{2}\right)$ RGCs (Supplementary Figure 2C). Concordantly, anti-Sema3E prevented the improved retinal vascularization in MSCs-CMtreated mice subjected to OIR (Figures $4 \mathrm{~B}-\mathrm{C}$ ). In addition, treatment of mice subjected to OIR with recombinant Sema3E 

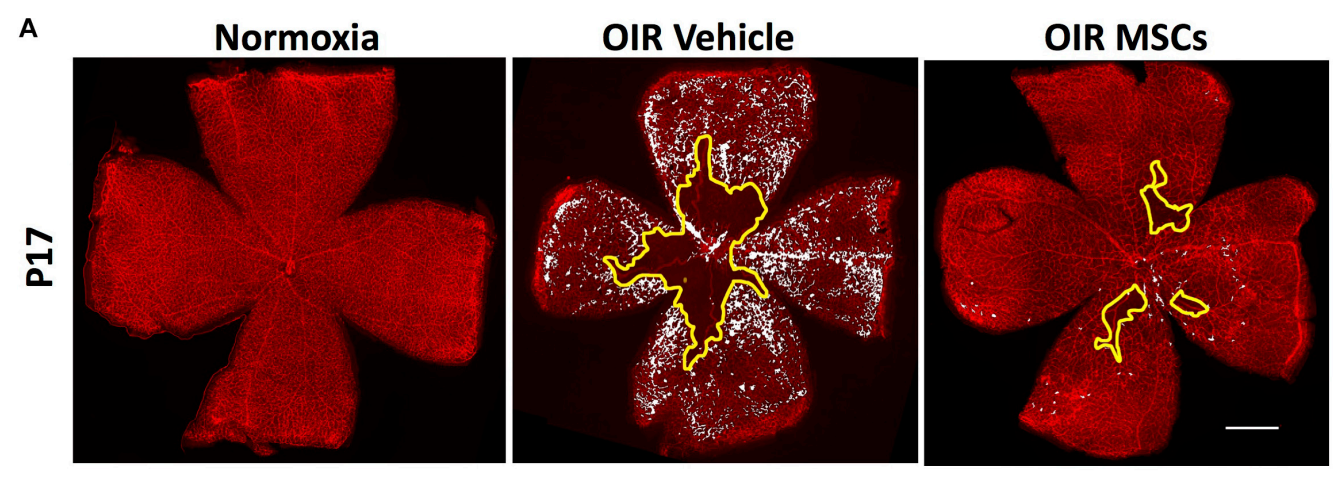

B

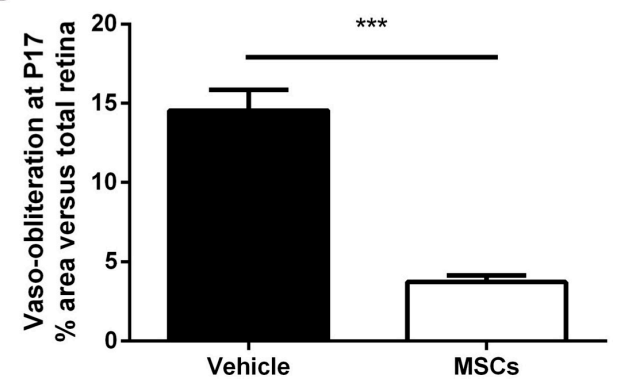

C

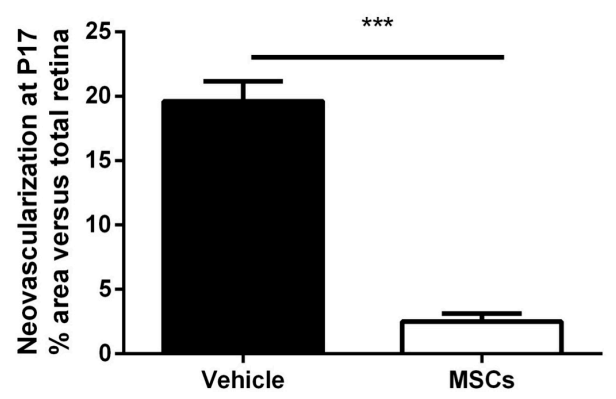

FIGURE 1 | Intravitreal injection of MSCs induced revascularization in OIR retinas. (A) Representative photomicrographs from isolectin B4-stained retinal flatmounts from normoxic or OIR mice at P17 intravitreally treated with vehicle or MSCs. Scale bar $500 \mu \mathrm{m}$. (B) Retinas intravitreally injected with MSCs demonstrate decreased vaso-obliterated (VO) areas (outlined with solid yellow) with respect to OIR vehicle at P17. Quantification of VO areas is shown in graph ( ${ }^{\star \star \star} p<0.001$ vs vehicle, values are mean \pm SEM, $n=6-10$ retinas). (C) MSCs-treated OIR retinas further show less neovascularization (NV) areas (highlighted in white) compared to vehicle. Quantification of NV areas by SWIFT_NV are shown in graphs ( ${ }^{\star * \star} p<0.001$ vs vehicle, values are mean $\pm \mathrm{SEM}, n=6-10$ retinas).

(rSema3E, at P12) markedly curtailed aberrant NV (at P17), in line with a gradual OIR-associated increase in the expression of the Sema3E receptor PlexinD1 (Supplementary Figure 3A); yet surprisingly anti-angiogenic Sema3E also diminished the degree of retinal vasoobliteration (Figures $5 \mathrm{~A}-\mathrm{C}$ ).

\section{Effects of MSCs-CM and Sema3E in OIR Are Associated With Downregulation of Angio-Active IL-17A and Other Proinflammatory Cytokines in Myeloid Cells}

As is the case for MSCs (Qian et al., 2020), Sema3E does not only act on endothelial cells ( $\mathrm{Gu}$ et al., 2005), by inhibiting directly proangiogenic effects of IL-17A (Supplementary Figure 3B), but also exerts effects on myeloid cells (Mohammed et al., 2020). In an attempt to explain opposing actions of Sema3E on vasculature we explored if Sema3E can regulate inflammatory mediators (myeloid cell-derived) which exhibit distinct functions. A lack of Sema3E has been shown to aggravate inflammation (Movassagh et al., 2017a,b) and exacerbate neovascular retinopathy by increasing the release of pro-inflammatory cytokines, particularly the pro-angiogenic IL-17A (Talia et al., 2016). As expected, IL17A mRNA and protein (immunoreactivity) increased during the neovascular phase starting at P14 $(\mathrm{p}<0.05)$ and furthermore by $\mathrm{P} 17(P<0.001)$ (Figures $\mathbf{6 A}, \mathbf{B})$; likewise, mRNA expression of the retinoic acid receptor-related orphan nuclear receptor $\gamma$ $(\operatorname{ROR} \gamma)$, a key regulator in the production of IL-17A (Talia et al., 2016), also increased at P17 in OIR (Figure 6C). Intravitreal injection of MSCs-CM or rSema3E reduced significantly mRNA and protein levels of IL-17A, and mRNA expression of ROR $\gamma$ (Figures 6D,E) as well as that of other downstream proinflammatory cytokines IL-1 $\beta$, IL-6, and TNF- $\alpha$ (Supplementary Figure 4A), in OIR retinas evaluated at P17; importantly, contrary to IL-17A, IL-1 $\beta$ elicits retinal vascular degeneration by upregulating Sema3A (Rivera et al., 2013).

IL-17A co-localized with F4/80 myeloid cells in the retina, as these are main producers of IL-17A (Talia et al., 2016). Attenuation of the pro-inflammatory cytokine profile of myeloid cells by MSCs-CM and rSema3E, was not related to their density (flow cytometry analysis) (Supplementary Figure 4B), suggesting that MSCs-CM and rSema3E modulate activation state of immune cells rather than infiltration rate of these cells. Correspondingly, we found in PlexinD1-expressing BMDM 

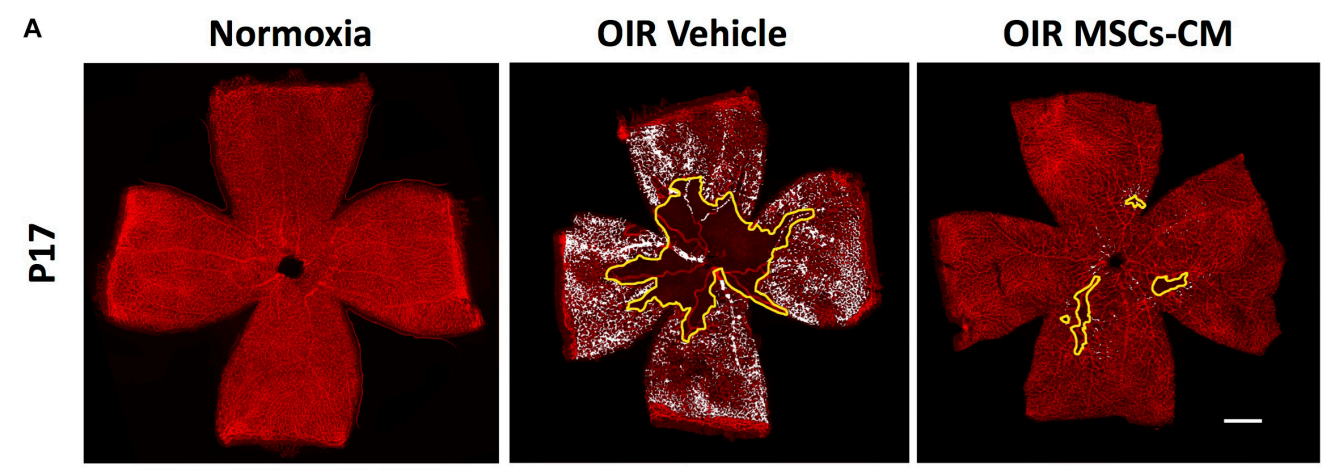

B

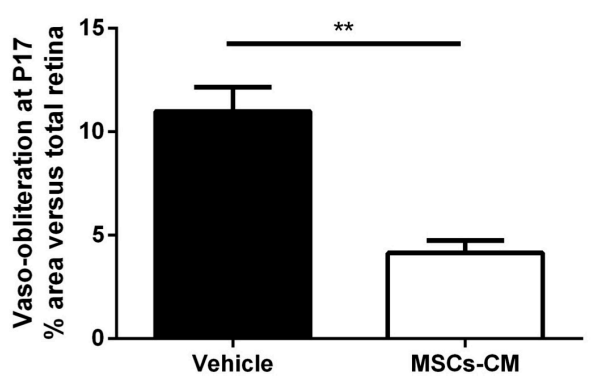

C

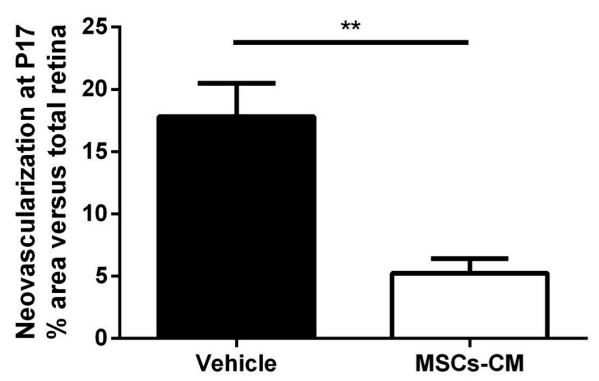

FIGURE 2 | Conditioned media (CM) of hypoxic MSC (MSCs-CM) promoted vascular growth in OIR retinas. (A) Representative photomicrographs from isolectin B4-stained retinal flatmounts from normoxic or OIR mice at P17 intravitreally treated with vehicle or MSCs-CM. Scale bar $500 \mu m$. Retinas intravitreally injected with MSCs-CM demonstrate decreased VO (B) and NV (C) areas highlighted in yellow and white, respectively. Quantification of VO and NV is represented in the graphs $\left({ }^{\star \star} p<0.01\right.$ vs vehicle, values are mean $\pm \mathrm{SEM}, n=6-10$ retinas).

(Wanschel et al., 2013) that hypoxia-driven IL-17A mRNA expression (Supplementary Figure 4C) was dose-dependently reduced by rSema3E (Figure 7A). Concordant protein expression of IL-17A and of IL-1 $\beta$, IL-6, and TNF- $\alpha$ was also decreased in vitro by rSema3E as well as MSCs-CM (Figures $7 \mathbf{B}, \mathbf{C}$ ), as observed in vivo (Supplementary Figure 4A); relevantly, IL$17 \mathrm{~A}$ induced expression of IL-1 $\beta$, IL-6, and TNF- $\alpha$ in BMDM (Figure 7D). Correspondingly in retinas of mice subjected to OIR, expression of IL- $1 \beta$ and IL-1 $\beta$-dependent Sema3A (Joyal et al., 2011; Rivera et al., 2013) were attenuated by anti-IL-17A antibody (Supplementary Figure 5A), consistent with induction of IL-1 $\beta$ by IL-17A (Figure 7D).

Finally, we ascertained a prominent role for MSCs-CMtriggered Sema3E derived from RGC, in suppressing IL-17A mRNA expression in myeloid cells; this effect was abrogated by anti-Sema3E (Figure 7E). Vice versa, the expression of the Sema3E and its receptor was unaffected by IL-17A or anti-IL-17A (Supplementary Figures 5A,B).

\section{DISCUSSION}

Progression of IRs is driven by a complex interplay of factors that activate various signaling pathways involved in dysregulation of vascular, inflammatory, neuronal and metabolic processes (Capitão and Soares, 2016; Rivera et al., 2017a). The ability to target critical factors involved in initial vascular damage and subsequent disoriented vessel formation remains a major challenge for preventing such oculo-vascular diseases. Emerging therapies against IRs often focus on targeting VEGF to ameliorate pathological NV and prevent vision loss; however, anti-VEGF therapy has limited benefits and can exert potential adverse outcomes (Ghasemi Falavarjani and Nguyen, 2013; Ferrara and Adamis, 2016). Alternatively, stem-cell based therapies offer a multifaceted therapeutic approach by targeting multiple underlying pathologic pathways and providing an environment favorable for vascular regeneration. In this study, we harnessed the reparative, regenerative and immunomodulatory potential of MSCs-secretome to promote proper vascular growth in ischemic retinas and prevent pathological neovascular formation. Several studies have shown that the therapeutic effects of MSCs can be associated with soluble paracrine factors and show even better tissue repair than the cells themselves (Uemura et al., 2006; Timmers et al., 2011; Liang et al., 2014; Pankajakshan and Agrawal, 2014; Pokrovskaya et al., 2020). MSCs-secretome has shown a low risk of toxicity, and immune rejection (Baek et al., 2019) making it a promising therapeutic alternative for the treatment of IRs. We investigated the modulatory response of the 


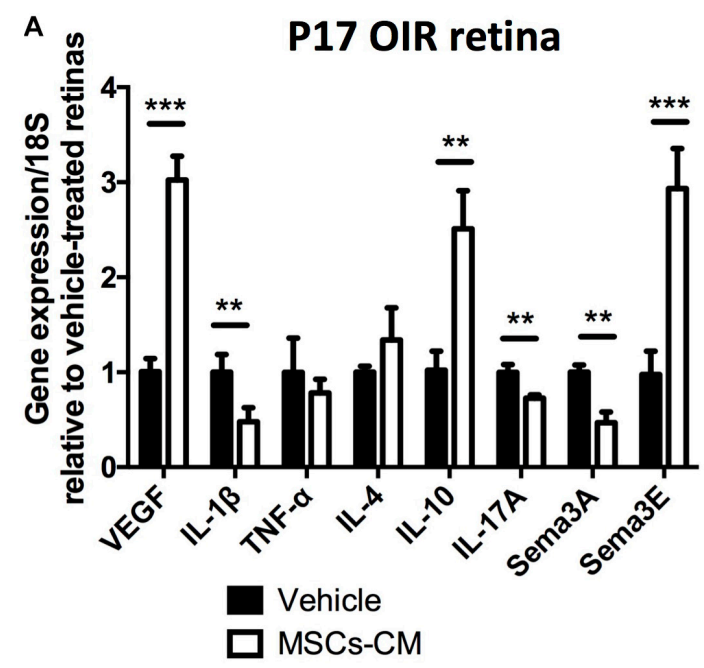

B

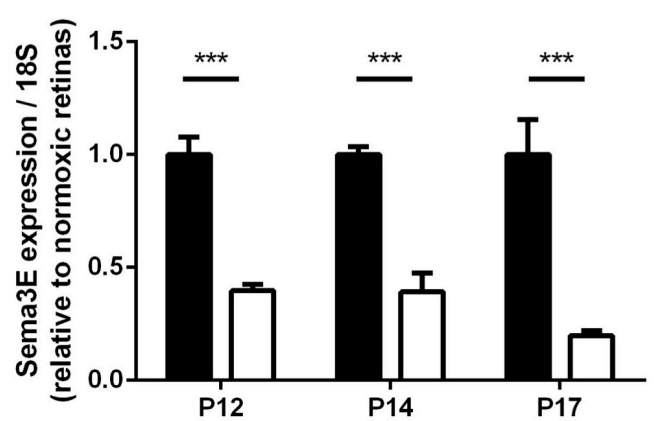

C

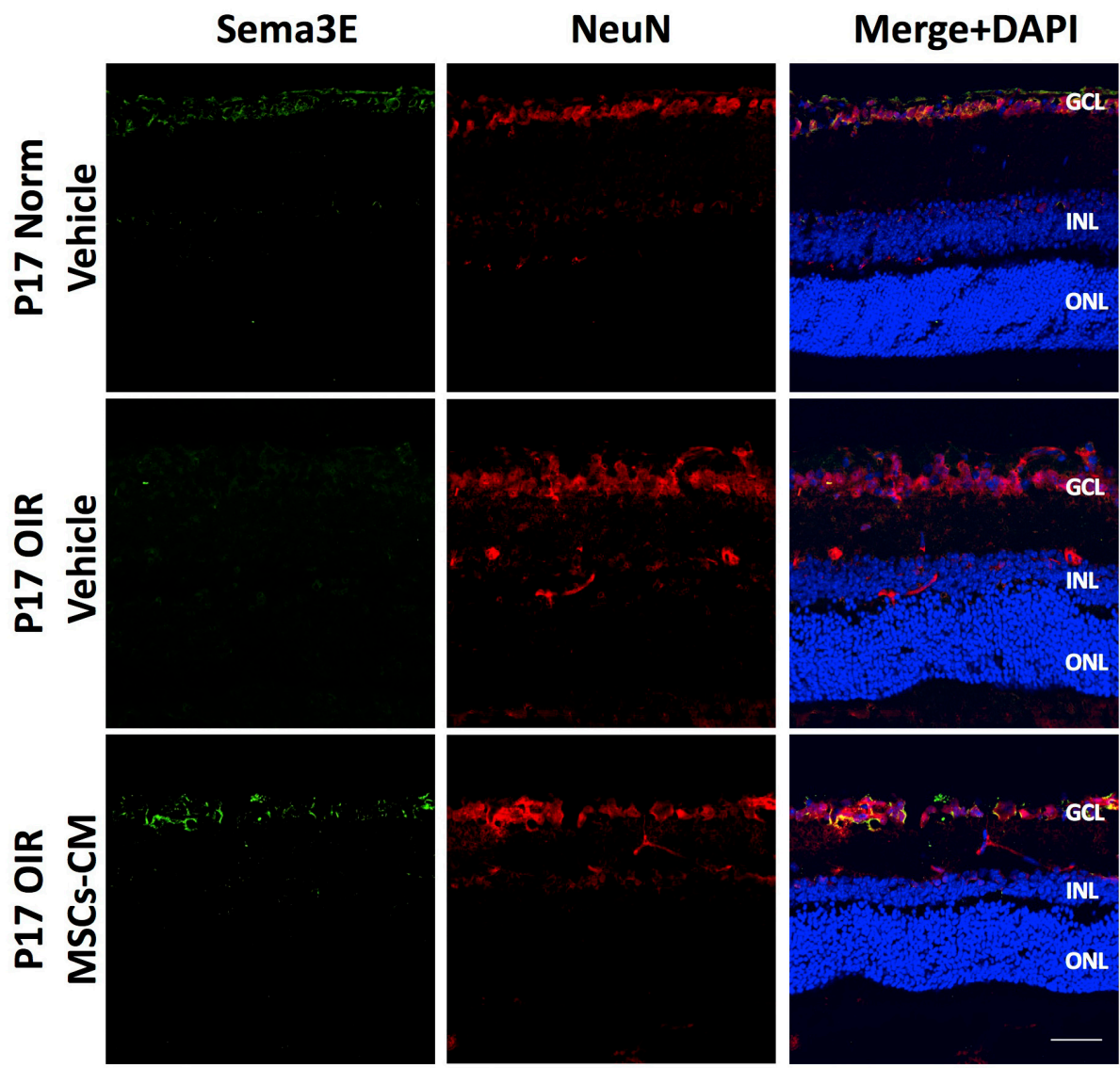

FIGURE 3 | MSCs-CM regulate gene expression and restored Sema3E levels in OIR retinas. (A) Real-time quantitative PCR (qPCR) analysis of whole retinas from P17 OIR mice treated with MSCs-CM show, in comparison with vehicle-treated retinas, regulated mRNA levels of growth factor (VEGF), inflammatory cytokines (IL-1 $\beta$, TNF- $\alpha, I L-4, I L-10$, and IL-17A), and guidance cues (Sema3A and Sema3E), $\left({ }^{\star \star} p<0.01,{ }^{\star \star \star} p<0.001\right.$ vs vehicle, values are mean \pm SEM, $n=4-5$, pool of 2 retinas per $n$ ). (B) Real-time quantitative PCR (qPCR) analysis of whole retinas from mice pups exposed to normoxia or OIR. Sema3E levels consistently decreased following exposure to $75 \% \mathrm{O}_{2}$ in $\mathrm{P} 12$, $\mathrm{P} 14$ and $\mathrm{P} 17$ pups ${ }^{* \star \star}=p<0.001$ vs normoxia, values are mean $\pm \mathrm{SEM}, n=4-5$, pool of 2 retinas per $\mathrm{n}$ ).

(C) Representative images showing immunohistochemical analysis of P17 mice exposed to OIR (middle panel and vehicle) displayed absence of Sema3E (green) levels in NeuN-expressing retinal ganglion cells (red) in comparison to normoxic retina (top panel, normoxia). Treatment of OIR retinas with MSCs-CM restored neuronal Sema3E levels (bottom panel). Nuclei were counterstained with DAPI (blue). GCL, ganglion cell layer; INL, inner nuclear layer; ONL, outer nuclear layer. Scale bar $100 \mu \mathrm{m}$. 
A

Hypoxic RGC-5 cells
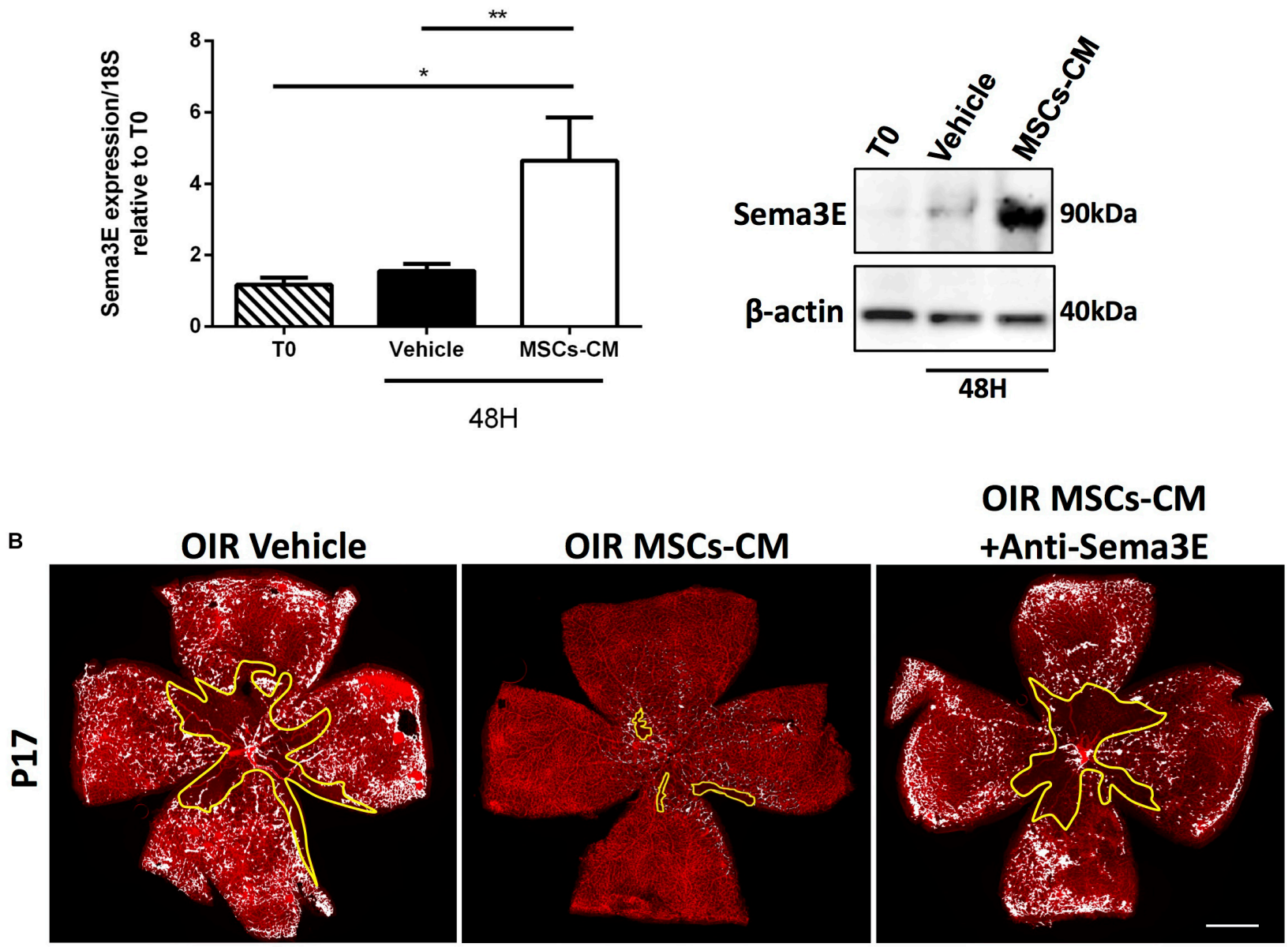

C

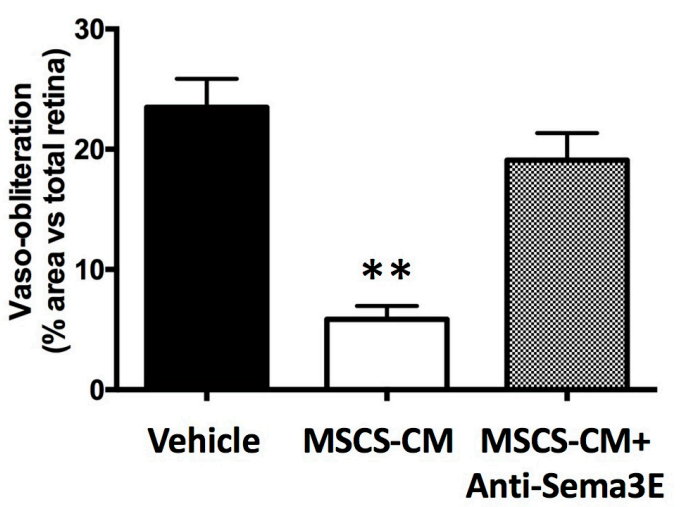

D

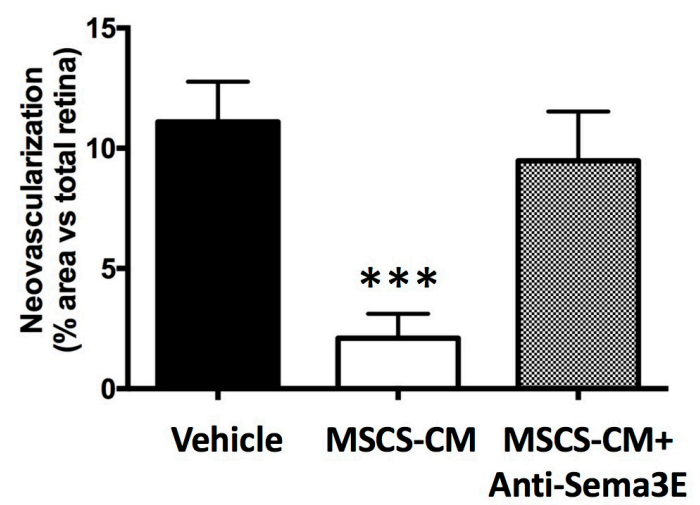

FIGURE 4 | Sema3E is promoted by MSCs-CM in retinal ganglion cells. (A) Sema3E levels were evaluated in lysates from RGC-5 cells subjected to MSCs-CM or vehicle for $48 \mathrm{~h}$ under hypoxic conditions. No changes were observed on RGC- 5 cells treated with vehicle, whereas MSCs-CM treatment upregulated mRNA levels evaluated by qPCR ${ }^{* \star}=p<0.01,{ }^{*}=p<0.05$ vs Vehicle, values are mean $\pm \mathrm{SEM}, n=4-5$, pool of 2 retinas per $n$ ) and protein levels of Sema3E evaluated by Western blot ( $n=4$, pool of 2 retinas per $n$ ). (B) Representative photomicrographs from isolectin B4-stained retinal flatmounts from P17 OIR mice treated intravitreally with vehicle (PBS) or MSCs-CM in absence or presence of an anti-Sema3E antibody. Scale bar $500 \mu \mathrm{m}$. Histograms representing VO (C) and NV areas (D) that were significantly reduced in MSCs-CM respect to vehicle-treated, but prevented in the presence of the anti-Sema3E $\left({ }^{\star *} p<0.01,{ }^{* \star *} p<0.001\right.$ vs vehicle, values are mean \pm SEM, $n=3-4$ retinas). 

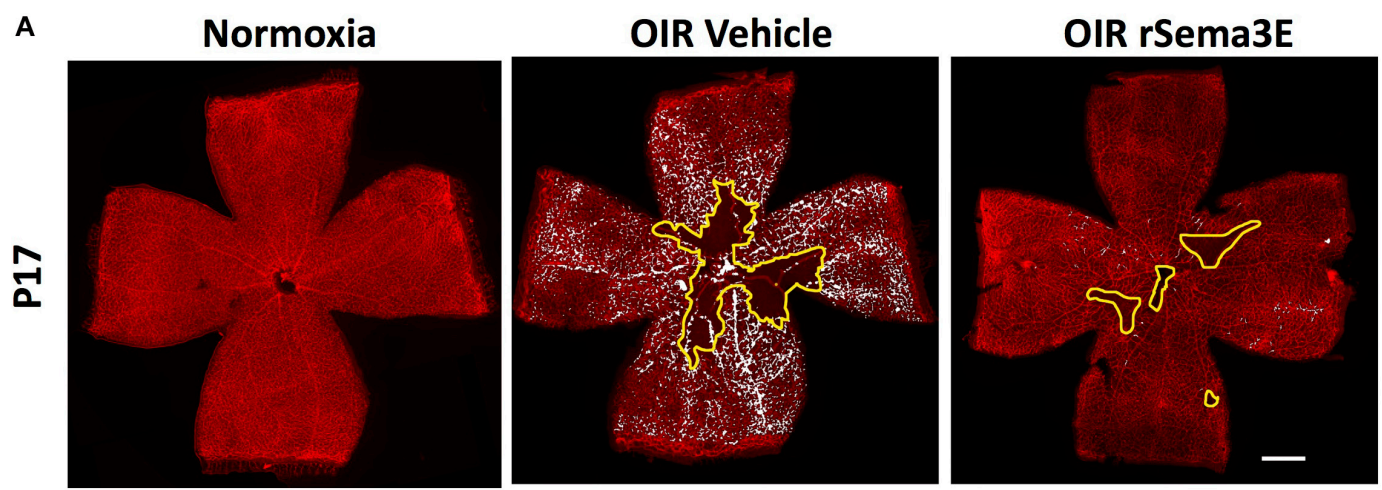

B

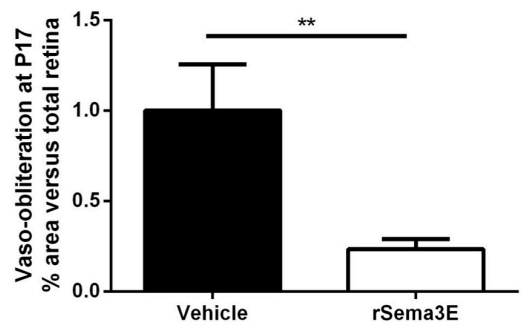

C

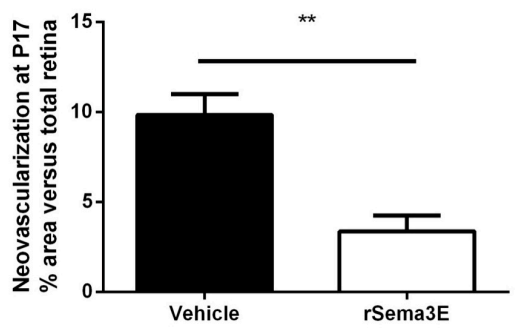

FIGURE 5 | Sema3E promoted vascular regeneration. (A) Representative photomicrographs from isolectin B4-stained retinal flatmounts from normoxic or P17 OIR mice treated intravitreally with vehicle (PBS) or recombinant Sema3E (rSema3E). Scale bar $500 \mu \mathrm{m}$. Histograms representing VO (B) and NV areas (C) that were significantly reduced in rSema3E-treated retinas in contrast to vehicle-treated ( ${ }^{\star *} p<0.01$ vs vehicle, values are mean \pm SEM, $n=4-5$ retinas).

MSCs-secretome on the expression of key retinal factors involved in vascular repair, notably in enhancing revascularization and thus reducing vasoobliteration. We found that MSCs-CM preventing the development of pathological NV and induced a healthy revascularization in OIR retinas. This beneficial effect of MSCs-CM was associated with a modulation of gene expression of angiogenic, guidance cue and inflammatory factors involved in the progression of retinopathy. Such restoration of growth as well as pro/anti-inflammatory factors, such as VEGF, IL-1, and IL-10, is reported to decrease the occurrence of retinopathy (Hellstrom et al., 2003; Higgins et al., 2003). Moreover, MSCs-CM controlled in opposite directions the expression of two neuron projection repulsive signals, Sema3A and Sema3E, known to exert anti-angiogenic properties, such that MSCs-CM induces Sema3E which in turn suppresses pro- and anti-angiogenic inflammatory factors, which, respectively, curtail pre-retinal NV and facilitate revascularization.

A variety of factors affected by the inherent environment have been identified to partake in reparative and immunomodulatory properties of MSCs. These include peptide growth factors, lipid mediators, nucleic acids as well as organelles and exosomes (Spees et al., 2016). A key factor presented in this work that partakes in benefits incurred by MSCs applies to Sema3E. Neuronal-derived Sema3E is markedly upregulated by MSCs-CM, and in turn exerts potent anti-inflammatory effects on myeloid cells which are the main producers of potentially detrimental cytokines (Demircan et al., 2006; Mocan et al., 2006; Rivera et al., 2013; Talia et al., 2016) that contribute to vascular injury and pathological NV (Karlstetter et al., 2015). The effects of Sema3E on macrophages are mostly controversial (Shimizu et al., 2013; Wanschel et al., 2013). In this paper MSCs-CM restores Sema3E, which tends to normalize IL-17A concentrations and in turn those of other proinflammatory cytokines, some of which upregulate expression of other Semaphorins, notably Sema3A (Joyal et al., 2011; Rivera et al., 2013). The mechanism by which Sema3E down-regulates IL-17A is possibly through suppression of ROR $\gamma$, an important regulator of IL-17A (Talia et al., 2016). IL-17A is known to play an important role in aggravating and sustaining local tissue inflammation by enhancing the inflammatory signaling pathways of pro-inflammatory cytokines that impede normal revascularization and enhance pathological NV (Xu and Cao, 2010; McGeachy et al., 2019). In contrast, IL- $1 \beta$ causes retinal vascular degeneration by inducing Sema3A expression (Rivera et al., 2013). The shift in the inflammatory profile of OIR retinas treated with MSCs-CM or rSema3E resulted in a beneficial advantage by favoring an environment suitable for vascular regeneration and dampening preretinal NV in the ischemic tissue.

Although we attribute a significant role for inflammatory mediators IL-17A, IL-1 $\beta$ and possibly IL- 6 and TNF- $\alpha$ in 

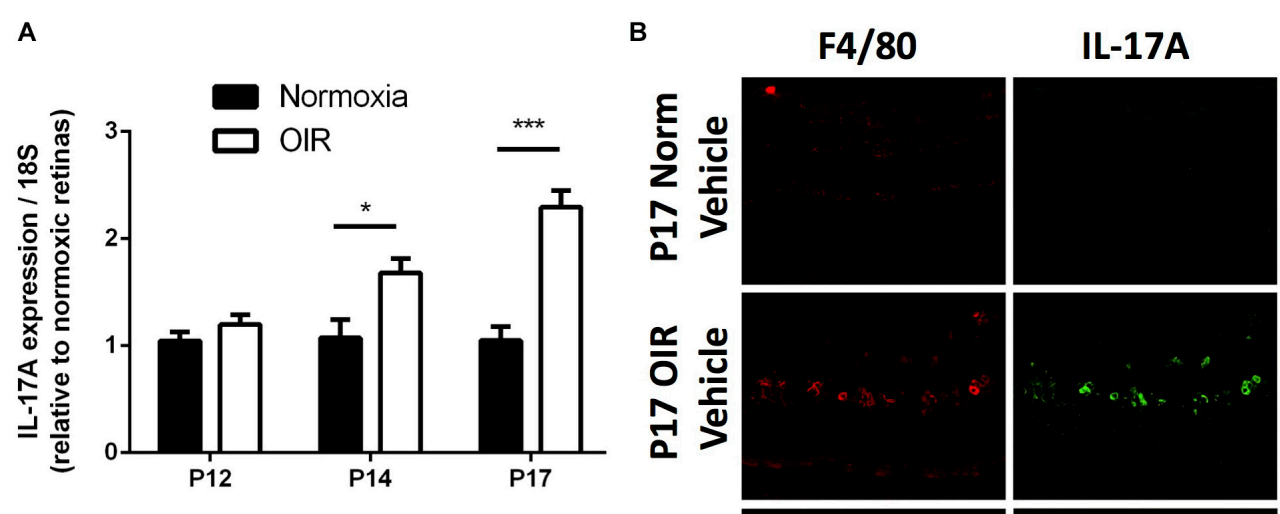

\section{Merge+DAPI}

C
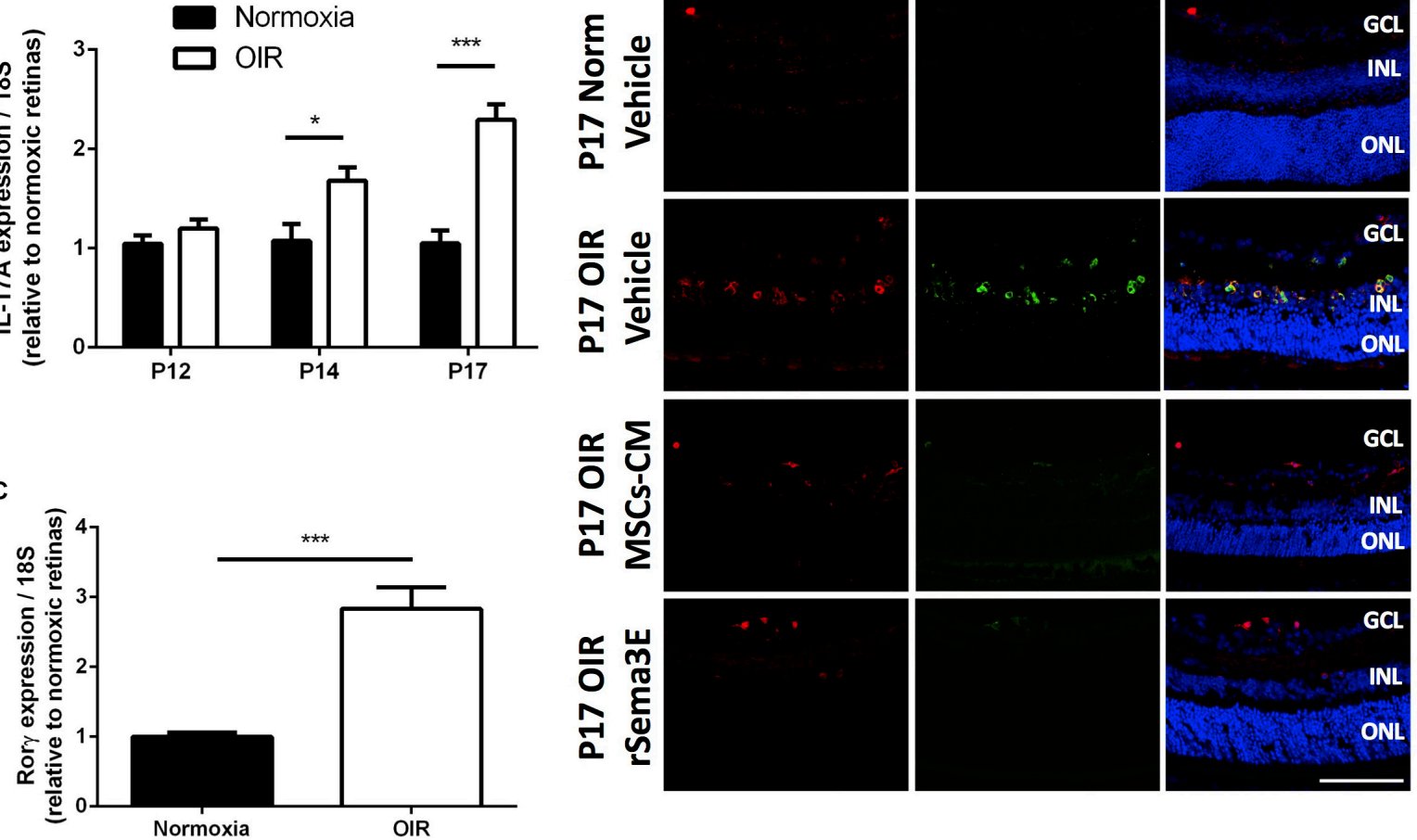

D

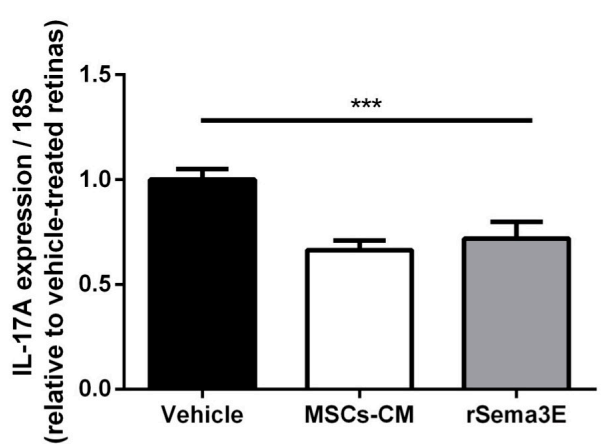

E

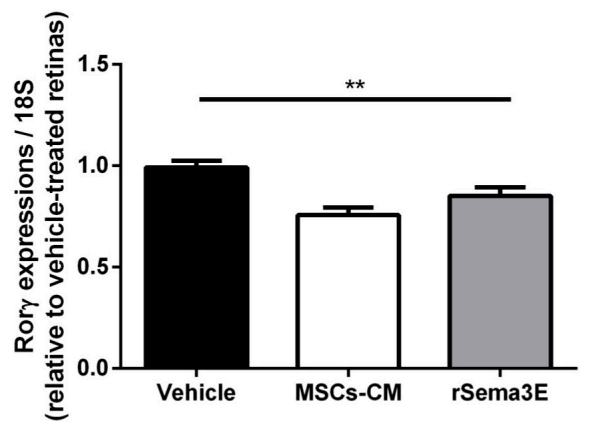

FIGURE 6 | MSCs-CM downregulated IL-17A levels in retinal myeloid cells. (A) QPCR analysis of IL-17A in whole retina from mice pups at different time points of OIR demonstrating increased levels of IL-17A mRNA by P14 and P17 ( ${ }^{*} p<0.05,{ }^{* \star *} p<0.001$ vs normoxia, values are mean \pm SEM, $n=4-5$, pool of 2 retinas per n). (B) Representative cryosections of normoxic and OIR retinas treated with Vehicle, MSCs-CM or rSema3E demonstrating co-localization of IL-17A with myeloid cell F4/80 marker. Nuclei were counterstained with DAPI (blue). NFL, nerve fiber layer; GCL, ganglion cell layer; INL, inner nuclear layer; ONL, outer nuclear layer. Scale bar $100 \mu \mathrm{m}$. (C) Real-time quantification (qPCR analysis) of P17 OIR retinas demonstrated increased expression of the nuclear receptor ROR $\gamma$ which regulates IL-17A transcription ( ${ }^{\star \star *} p<0.001$, values are mean \pm SEM, $n=4-5$, pool of 2 retinas per $\left.n\right)$. (D) Intravitreal injection of OIR retinas with MSCs-CM and $r S e m a 3 E$ demonstrated lower levels of IL-17A at P17 versus vehicle-injected OIR retinas ${ }^{* * *} p<0.001, n=3-4$, pool of 2 retinas per $\left.n\right)$. (E) Intravitreal injection of MSCs-CM and rSema3E exhibited significant decreased ROR $\gamma$ expression in OIR retinas via qPCR analysis at P17 in comparison to vehicle-treated counterpart $\left({ }^{* *} p<0.01\right.$, values are mean \pm SEM, $n=4-5$, pool of 2 retinas per $\mathrm{n}$ ).

the actions of MSCs-CM and Sema3E we cannot rule out the possible contribution of anti-inflammatory mediators, such as angiopoietin-like 4 (ANGPTL4) or IL-10 highly secreted by MSCs (Wang et al., 2018; Cho et al., 2019). Such factors could indirectly modulate Sema3E production through suppressing the secretion of proinflammatory cytokines (Fiorentino et al., 1991; Cho et al., 2019; Sun et al., 2019) which induce ROR- $\alpha$ upregulation and subsequently inhibit Sema3E expression in the retina during pathological conditions. ROR- $\alpha$ is up-regulated by pro-inflammatory cytokines such as IL-1 $\beta$ and TNF- $\alpha$ (Journiac et al., 2009; Cho et al., 2019) and suppresses Sema3E expression in pathological retinal NV (Fukushima et al., 2011; Kim et al., 2011). We can also not exclude an effect of this Semaphorin directly on its 
A Hypoxic BMDM
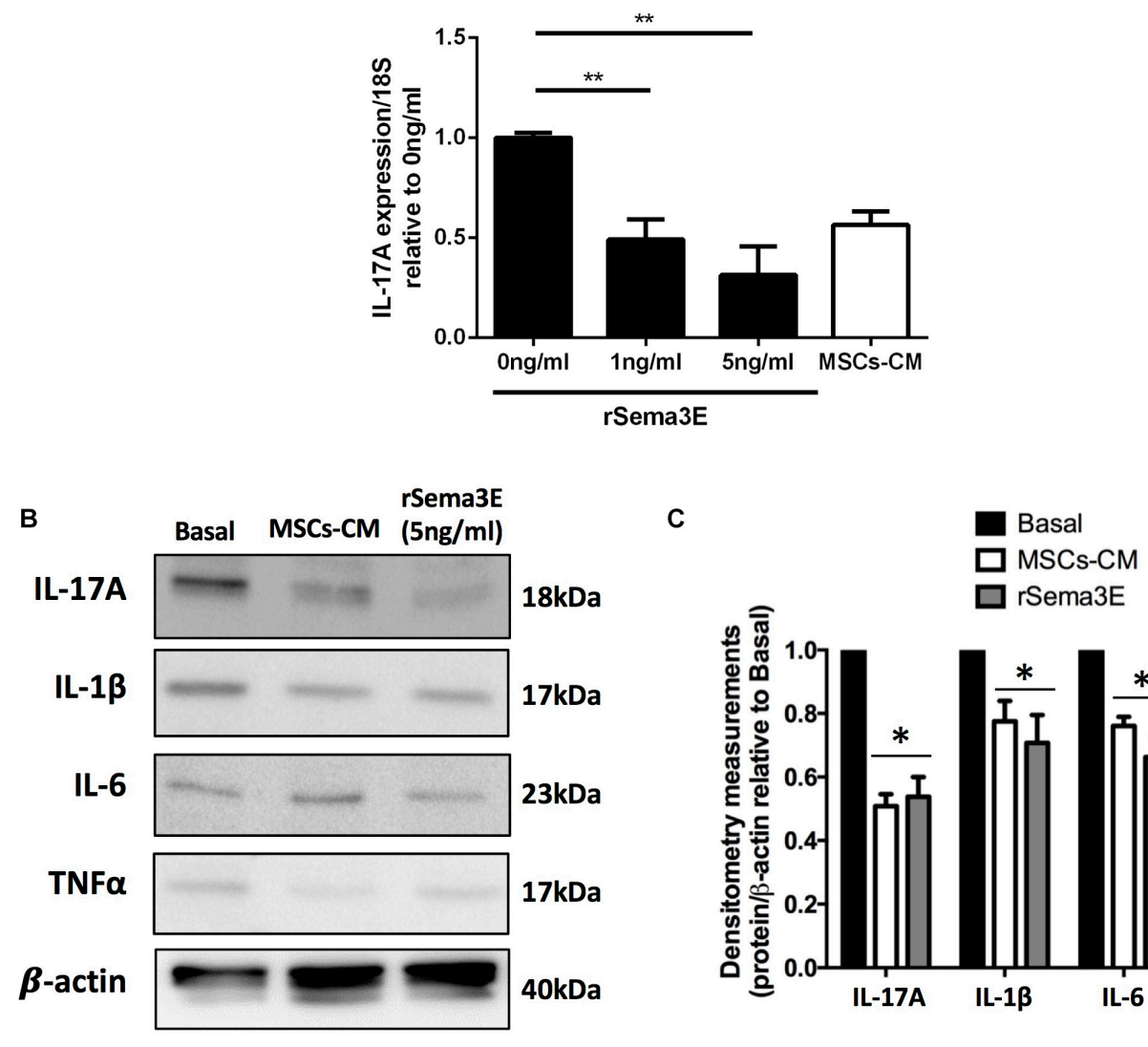

D

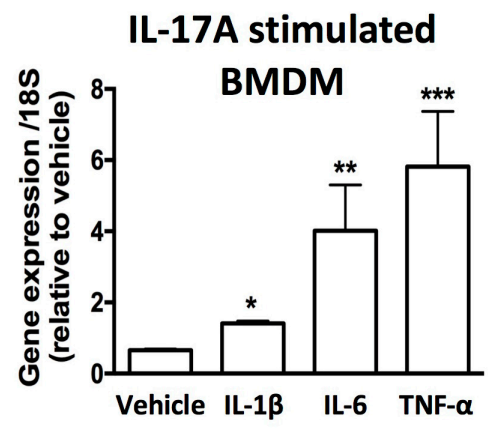

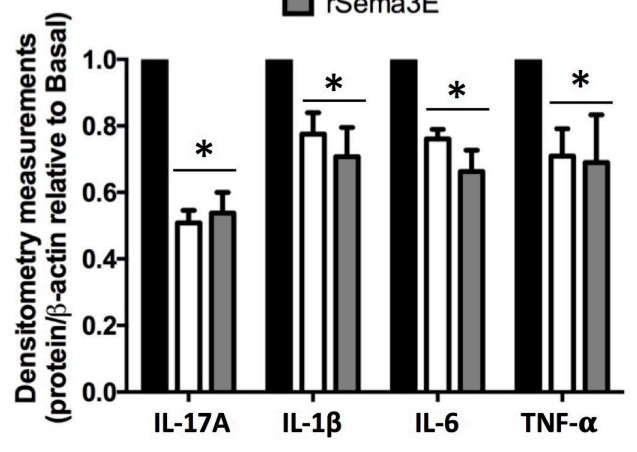

E

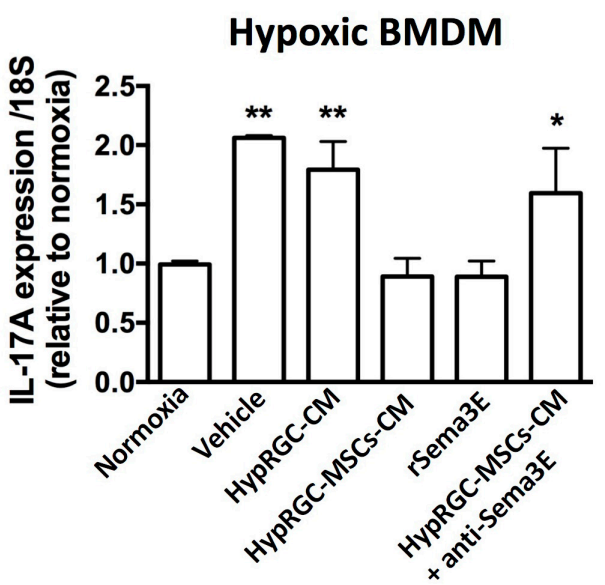

FIGURE 7 | rSema3E regulated myeloid cells-derived IL-17A in a dose-dependent manner. (A) Stimulation of hypoxic bone marrow-derived macrophages (BMDM) with $r$ Sema3E diminished IL-17A mRNA expression in a dose-dependent manner, while MSCs-CM have a partial effect $\left({ }^{* *} p<0.01 \mathrm{vs} 0 \mathrm{ng} / \mathrm{Sema} \mathrm{E}\right.$, values are mean $\pm \mathrm{SEM}, n=6$ ). (B) Representative images from Western blot analysis of pro-inflammatory cytokines (IL-17A, IL-1 $\beta$, IL-6, and TNF- $\alpha$ ) in hypoxic BMDM treated with MSCs-CM and rSema3E $(5 \mathrm{ng} / \mathrm{ml})$ showing reduced protein levels of the cytokines with rSema3E and MSCs-CM treatments in comparison to vehicle. $\beta$-actin was used as internal control. (C) Densitometry quantification at right ${ }^{*}<0.05$ vs Basal, values are mean $\pm \mathrm{SEM} n=3$ independent experiments, pool of 2 wells per group). (D) Stimulation of hypoxic BMDM with rlL-17A (100 ng/ml) increases IL-1 $1 \beta$, IL-6, and TNF- $\alpha$ mRNA expression $\left({ }^{*} p<0.05,{ }^{* *} p<0.01\right.$, ${ }^{* \star *} p<0.001 \mathrm{vs}$ vehicle, values are mean \pm SEM, $n=3$ ). (E) Real-time quantitative PCR (qPCR) analysis of bone marrow-derived macrophages (BMDM) pre-exposed to hypoxia (5\% $\mathrm{O}_{2}$ ) showing the augmented BMDMs-derived IL-17A expression in vehicle (DMEM alone) and hypoxic RGC conditioned media (HypRGC-CM) treatments after $24 \mathrm{~h}$ of incubation. BMDMs treated with the conditioned medium derived from RGCs previously stimulated with MSCs-CM (HypRGC-MSCs-CM) strongly supressed $(p<0.01)$ the mRNA levels of IL-17A in a similar way to the supplementation with the rSema3E $(5 \mathrm{ng} / \mathrm{ml})$. The anti-inflammatory effect of HypRGC-MSCs-CM was abrogated in the presence of a neutralizing antibody against Sema3E $\left({ }^{\star} p<0.05,{ }^{* \star} p<0.01\right.$, vs normoxia, values are mean $\left.\pm \operatorname{SEM}, n=3\right)$. 
receptor PlexinD1 on endothelium (Fukushima et al., 2011; Kim et al., 2011; Suda et al., 2014). PlexinD1 activation promotes filopodial retraction in endothelial tip cells by disrupting integrin-mediated adhesive structures resulting in inhibition of angiogenesis (Sakurai et al., 2010). Its expression is particularly augmented in pathological endothelium as found herein. Altogether, these claims favor PlexinD1 as a viable target in abnormal conditions, relative to VEGF essential in vascular proliferation.

In this study, we unveiled an unprecedented interplay between MSCs, neurons and myeloid cells through which MSCs inhibit aberrant NV and promote revascularization in retinopathy, at least in part, by restoring neuronal Sema3E levels and reducing pathological levels of IL-17A in myeloid cells. A limitation in this study is uncovering the identity of MSCs-derived factors that trigger Sema3E production in RGCs. In this regard, MSCs-derived exosomes and microvesicles (Bruno et al., 2015; Rani et al., 2015) that contain a complex set of multiple soluble biologically active molecules could be ideal candidates to regulate Semaphorins in RGCs. The therapeutic efficacy of extracellular vesicles from MSCs has been widely demonstrated in many retinal disease models (Yu et al., 2016; Mead and Tomarev, 2017; Moisseiev et al., 2017; He et al., 2018; Mead et al., 2018; Pan et al., 2019). Due to their nano dimension, extracellular vesicles may rapidly reach and exert their therapeutic effects on
RGCs (Harrell et al., 2018) inducing axonal regeneration and improving survival and the maintenance of these cells (Seyedrazizadeh et al., 2020; Usategui-Martin et al., 2020). Notably, microRNAs (miRNAs) as a component of MSCs-derived extracellular microvesicles (Park et al., 2018; Asgarpour et al., 2020) seem to be attractive candidates for semaphorins regulation on RGCs. miRNAs have been shown to modulate semaphorin expression, for instance, miR-497$5 \mathrm{p}$ is a critical target of Sema3A (Shapoori et al., 2019) while miRNA-4282 has been shown to be a key regulator of Sema3E expression (Kang et al., 2016). Determining the presence of these miRNAs as part of MSCs-secretome could be of great relevance for evaluating its action on RGCs. Exosome-derived lipids could be other candidates for regulating semaphorins in RGCs. Exosomes contain large amounts of cholesterols (de Gassart et al., 2003; Deng et al., 2018). Cholesterol derivatives such as $7 \alpha$-hydroxycholesterol, $7 \beta$-hydroxy-cholesterol and 7-keto-cholesterol are natural ligands and negative regulators of the nuclear receptor RORalpha (Solt and Burris, 2012), responsible for inhibiting the expression of Sema3E in RGCs during OIR (Sun et al., 2017). Although we do not rule out a possible action of MSCs-derived cytokines/growth factors on RGCs, future work will certainly be aimed at evaluating the MSCs-CM-derived extracellular vesicle elements involved in the regulation of semaphorins in RGCs. So far, our study shows the ability

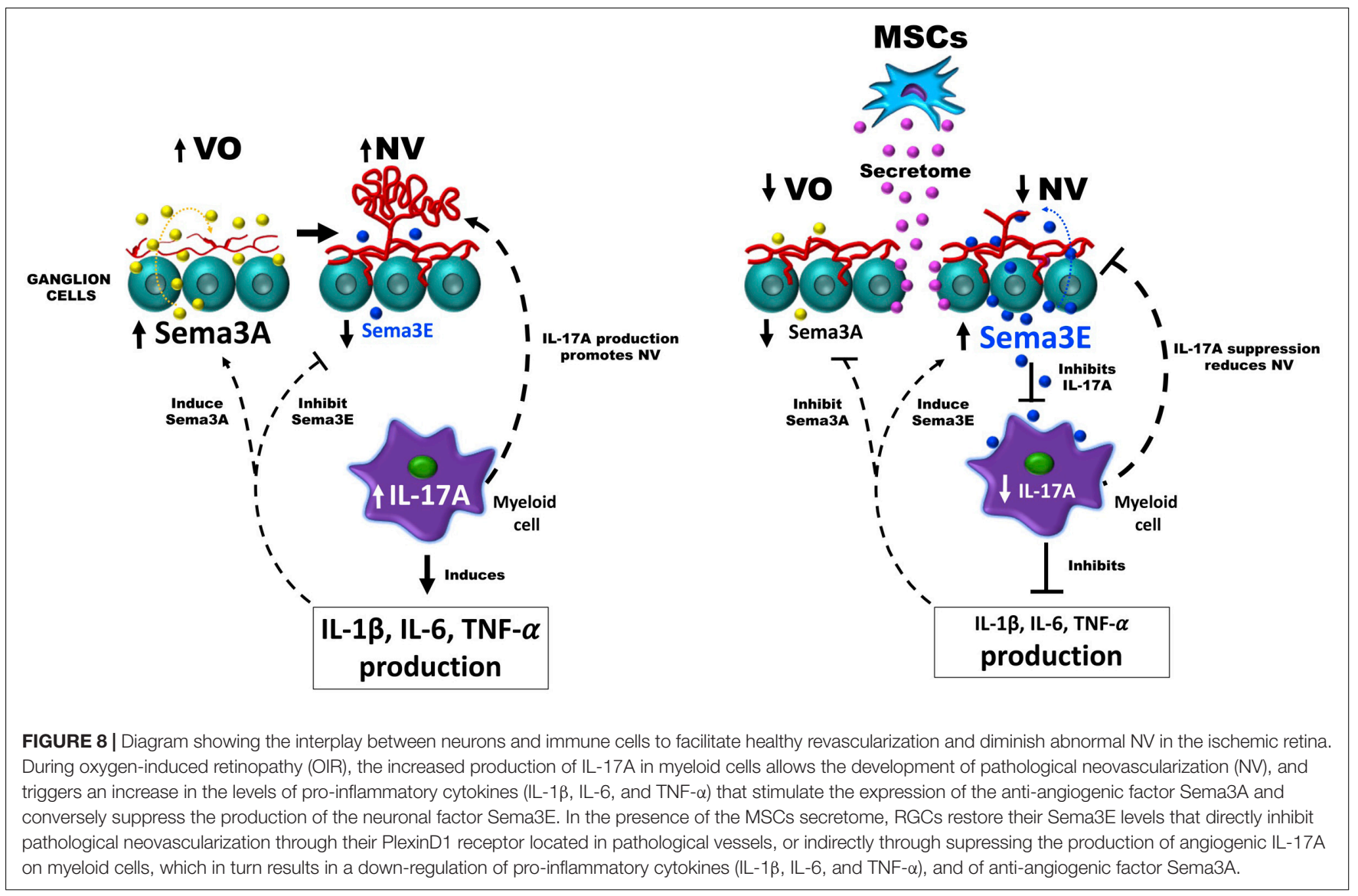


of MSCs-CM to promote the production of neuronal factors involved in immunomodulatory activities which would generate a microenvironment permissive for vascular regeneration, and thus offer a promising opportunity for the treatment of IRs using stem cell therapy. Collectively, we show evidence by which MSC secretome regulates the interplay between neurons and immune cells establishing a healthy environment permissive for vascular regeneration in ischemic retina; a schematic diagram depicting the described mode of action of MSCs secretome in ischemic retinopathy is presented in Figure 8.

\section{DATA AVAILABILITY STATEMENT}

The original contributions presented in the study are included in the article/Supplementary Material, further inquiries can be directed to the corresponding author/s.

\section{ETHICS STATEMENT}

The animal study was reviewed and approved by the Animal Care Committee of Maisonneuve-Rosemont Hospital in accordance with guidelines established by the Canadian Council on Animal Care and the Association for Research in Vision and Ophthalmology (ARVO) statement for the use of animals in ophthalmic and vision research.

\section{REFERENCES}

Adhikari, R., Chen, C., Waters, E., West, F. D., and Kim, W. K. (2018). Isolation and differentiation of mesenchymal stem cells from broiler chicken compact bones. Front. Physiol. 9:1892. doi: 10.3389/fphys.2018.01892

Alamri, A., Rahman, R., Zhang, M., Alamri, A., Gounni, A. S., and Kung, S. K. P. (2018). Semaphorin-3E produced by immature dendritic cells regulates activated natural killer cells migration. Front. Immunol. 9:1005. doi: 10.3389/ fimmu.2018.01005

Asgarpour, K., Shojaei, Z., Amiri, F., Ai, J., Mahjoubin-Tehran, M., Ghasemi, F., et al. (2020). Exosomal microRNAs derived from mesenchymal stem cells: cell-to-cell messages. Cell Commun. Signal. 18:149.

Baek, G., Choi, H., Kim, Y., Lee, H. C., and Choi, C. (2019). Mesenchymal stem cellderived extracellular vesicles as therapeutics and as a drug delivery platform. Stem Cells Transl. Med. 8, 880-886. doi: 10.1002/sctm.18-0226

Bertelli, P. M., Pedrini, E., Guduric-Fuchs, J., Peixoto, E., Pathak, V., Stitt, A. W., et al. (2020). Vascular regeneration for ischemic retinopathies: hope from cell therapies. Curr. Eye Res. 45, 372-384. doi: 10.1080/02713683.2019.1681004

Bracha, P., Moore, N. A., Ciulla, T. A., Wudunn, D., and Cantor, L. B. (2018). The acute and chronic effects of intravitreal anti-vascular endothelial growth factor injections on intraocular pressure: a review. Surv. Ophthalmol. 63, 281-295. doi: 10.1016/j.survophthal.2017.08.008

Bruno, S., Deregibus, M. C., and Camussi, G. (2015). The secretome of mesenchymal stromal cells: role of extracellular vesicles in immunomodulation. Immunol. Lett. 168, 154-158. doi: 10.1016/j.imlet.2015.06.007

Buehler, A., Sitaras, N., Favret, S., Bucher, F., Berger, S., Pielen, A., et al. (2013). Semaphorin 3F forms an anti-angiogenic barrier in outer retina. FEBS Lett. 587, 1650-1655. doi: 10.1016/j.febslet.2013.04.008

Capitão, M., and Soares, R. (2016). Angiogenesis and inflammation crosstalk in diabetic retinopathy. J. Cell. Biochem. 117, 2443-2453. doi: 10.1002/jcb.25575

Caroti, C. M., Ahn, H., Salazar, H. F., Joseph, G., Sankar, S. B., Willett, N. J., et al. (2017). A novel technique for accelerated culture of murine mesenchymal stem cells that allows for sustained multipotency. Sci. Rep. 7:13334.

\section{AUTHOR CONTRIBUTIONS}

$\mathrm{BN}, \mathrm{SC}$, and JCR conceived and designed the study and wrote the manuscript. $\mathrm{BN}, \mathrm{JCR}, \mathrm{RD}, \mathrm{PA}, \mathrm{SO}$, and IL performed the experiments. $\mathrm{BN}$ and JCR prepared the figures. JCR designed the scheme. All authors contributed to the article and approved the submitted version.

\section{FUNDING}

SC holds a Canada Research Chair (Vision Science) and the Leopoldine Wolfe Chair in translational research in age-related macular degeneration.

\section{ACKNOWLEDGMENTS}

The authors thank Martine Blais for her initial participation in this study; Martine Dupuis for flow cytometry; and the animal care facility for mice husbandry.

\section{SUPPLEMENTARY MATERIAL}

The Supplementary Material for this article can be found online at: https://www.frontiersin.org/articles/10.3389/fcell.2021. 630645/full\#supplementary-material

Cho, D. I., Kang, H. J., Jeon, J. H., Eom, G. H., Cho, H. H., Kim, M. R., et al. (2019). Antiinflammatory activity of ANGPTL4 facilitates macrophage polarization to induce cardiac repair. JCI Insight 4:e125437. doi: 10.1172/jci.insight.125437

Connor, K. M., Krah, N. M., Dennison, R. J., Aderman, C. M., Chen, J., Guerin, K. I., et al. (2009). Quantification of oxygen-induced retinopathy in the mouse: a model of vessel loss, vessel regrowth and pathological angiogenesis. Nat. Protoc. 4, 1565-1573. doi: 10.1038/nprot.2009.187

de Gassart, A., Geminard, C., Fevrier, B., Raposo, G., and Vidal, M. (2003). Lipid raft-associated protein sorting in exosomes. Blood 102, 4336-4344. doi: 10. 1182/blood-2003-03-0871

Demircan, N., Safran, B. G., Soylu, M., Ozcan, A. A., and Sizmaz, S. (2006). Determination of vitreous interleukin-1 (IL-1) and tumour necrosis factor (TNF) levels in proliferative diabetic retinopathy. Eye (Lond.) 20, 1366-1369. doi: 10.1038/sj.eye.6702138

Deng, H., Sun, C., Sun, Y., Li, H., Yang, L., Wu, D., et al. (2018). Lipid, protein, and microrna composition within mesenchymal stem cell-derived exosomes. Cell Reprogram. 20, 178-186. doi: 10.1089/cell.2017.0047

Ding, S. L. S., Kumar, S., and Mok, P. L. (2017). Cellular reparative mechanisms of mesenchymal stem cells for retinal diseases. Int. J. Mol. Sci. 18:1406. doi: 10.3390/ijms18081406

Dominici, M., Le Blanc, K., Mueller, I., Slaper-Cortenbach, I., Marini, F., Krause, D., et al. (2006). Minimal criteria for defining multipotent mesenchymal stromal cells. the international society for cellular therapy position statement. Cytotherapy 8, 315-317. doi: 10.1080/14653240600855905

Dorrell, M. I., Otani, A., Aguilar, E., Moreno, S. K., and Friedlander, M. (2004). Adult bone marrow-derived stem cells use R-cadherin to target sites of neovascularization in the developing retina. Blood 103, 3420-3427. doi: 10 . 1182/blood-2003-09-3012

Ferrara, N., and Adamis, A. P. (2016). Ten years of anti-vascular endothelial growth factor therapy. Nat. Rev. Drug Discov. 15, 385-403. doi: 10.1038/nrd.2015.17

Fiorentino, D. F., Zlotnik, A., Mosmann, T. R., Howard, M., and O'garra, A. (1991). IL-10 inhibits cytokine production by activated macrophages. J. Immunol. 147, 3815-3822. 
Fukushima, Y., Okada, M., Kataoka, H., Hirashima, M., Yoshida, Y., Mann, F., et al. (2011). Sema3E-PlexinD1 signaling selectively suppresses disoriented angiogenesis in ischemic retinopathy in mice. J. Clin. Invest. 121, 1974-1985. doi: $10.1172 /$ jci44900

Ghasemi Falavarjani, K., and Nguyen, Q. D. (2013). Adverse events and complications associated with intravitreal injection of anti-VEGF agents: a review of literature. Eye 27, 787-794. doi: 10.1038/eye.2013.107

Gu, C., Yoshida, Y., Livet, J., Reimert, D. V., Mann, F., Merte, J., et al. (2005). Semaphorin 3E and Plexin-D1 control vascular pattern independently of neuropilins. Science 307, 265-268. doi: 10.1126/science.1105416

Harrell, C. R., Fellabaum, C., Arsenijevic, A., Markovic, B. S., Djonov, V., and Volarevic, V. (2019). Therapeutic potential of mesenchymal stem cells and their secretome in the treatment of glaucoma. Stem Cells Int. 2019:7869130.

Harrell, C. R., Simovic Markovic, B., Fellabaum, C., Arsenijevic, A., Djonov, V., Arsenijevic, N., et al. (2018). Therapeutic potential of mesenchymal stem cellderived exosomes in the treatment of eye diseases. Adv. Exp. Med. Biol. 1089, 47-57. doi: 10.1007/5584_2018_219

He, G. H., Zhang, W., Ma, Y. X., Yang, J., Chen, L., Song, J., et al. (2018). Mesenchymal stem cells-derived exosomes ameliorate blue light stimulation in retinal pigment epithelium cells and retinal laser injury by VEGF-dependent mechanism. Int. J. Ophthalmol. 11, 559-566.

Hellstrom, A., Engstrom, E., Hard, A. L., Albertsson-Wikland, K., Carlsson, B., Niklasson, A., et al. (2003). Postnatal serum insulin-like growth factor I deficiency is associated with retinopathy of prematurity and other complications of premature birth. Pediatrics 112, 1016-1020. doi: 10.1542/ peds.112.5.1016

Higgins, R. D., Yan, Y., Geng, Y., Sharma, J., and Barr, S. M. (2003). Captopril and vascular endothelial growth factor in a mouse model of retinopathy. Curr. Eye Res. 27, 123-129. doi: 10.1076/ceyr.27.2.123.15955

Ito, D., Nojima, S., and Kumanogoh, A. (2012). [Regulation of immune responses by immune semaphorins]. Nihon Rinsho 70, 1633-1643.

Jaimes, Y., Naaldijk, Y., Wenk, K., Leovsky, C., and Emmrich, F. (2017). Mesenchymal stem cell-derived microvesicles modulate lipopolysaccharidesinduced inflammatory responses to microglia cells. Stem Cells 35, 812-823. doi: $10.1002 /$ stem. 2541

Joe, A. W., and Gregory-Evans, K. (2010). Mesenchymal stem cells and potential applications in treating ocular disease. Curr. Eye Res. 35, 941-952. doi: 10.3109/ 02713683.2010 .516466

Journiac, N., Jolly, S., Jarvis, C., Gautheron, V., Rogard, M., Trembleau, A., et al. (2009). The nuclear receptor ROR(alpha) exerts a bi-directional regulation of IL-6 in resting and reactive astrocytes. Proc. Natl. Acad. Sci. U.S.A. 106, 21365-21370. doi: 10.1073/pnas.0911782106

Joyal, J.-S., Sitaras, N., Binet, F., Rivera, J. C., Stahl, A., Zaniolo, K., et al. (2011). Ischemic neurons prevent vascular regeneration of neural tissue by secreting semaphorin 3A. Blood 117, 6024-6035. doi: 10.1182/blood-2010-10-311589

Kang, X., Wang, M., Wang, H., Shen, X., and Guan, W. (2016). MiR-4282 suppresses proliferation and mobility of human colorectal carcinoma cells by targeting semaphorin 3E. Panminerva Med. 58, 197-205.

Karlstetter, M., Scholz, R., Rutar, M., Wong, W. T., Provis, J. M., and Langmann, T. (2015). Retinal microglia: just bystander or target for therapy? Prog. Retin. Eye Res. 45, 30-57. doi: 10.1016/j.preteyeres.2014.11.004

Kermarrec, L., Eissa, N., Wang, H., Kapoor, K., Diarra, A., Gounni, A. S., et al. (2019). Semaphorin-3E attenuates intestinal inflammation through the regulation of the communication between splenic CD11C+ and CD4+CD25T-cells. Br. J. Pharmacol. 176, 1235-1250. doi: 10.1111/bph.14614

Kim, J., Oh, W. J., Gaiano, N., Yoshida, Y., and Gu, C. (2011). Semaphorin 3EPlexin-D1 signaling regulates VEGF function in developmental angiogenesis via a feedback mechanism. Genes Dev. 25, 1399-1411. doi: 10.1101/gad. 2042011

Konala, V. B. R., Mamidi, M. K., Bhonde, R., Das, A. K., Pochampally, R., and Pal, R. (2016). The current landscape of the mesenchymal stromal cell secretome: a new paradigm for cell-free regeneration. Cytotherapy 18, 13-24. doi: 10.1016/j. jcyt.2015.10.008

Kruger, R. P., Aurandt, J., and Guan, K. L. (2005). Semaphorins command cells to move. Nat. Rev. Mol. Cell Biol. 6, 789-800. doi: 10.1038/nrm1740

Li, Y., and Zhou, Y. (2019). Interleukin-17: the role for pathological angiogenesis in ocular neovascular diseases. Tohoku J. Exp. Med. 247, 87-98. doi: 10.1620/ tjem. 247.87
Liang, X., Ding, Y., Zhang, Y., Tse, H. F., and Lian, Q. (2014). Paracrine mechanisms of mesenchymal stem cell-based therapy: current status and perspectives. Cell Transplant. 23, 1045-1059. doi: 10.3727/096368913x66 7709

Low, A., Faridi, A., Bhavsar, K. V., Cockerham, G. C., Freeman, M., Fu, R., et al. (2019). Comparative effectiveness and harms of intravitreal antivascular endothelial growth factor agents for three retinal conditions: a systematic review and meta-analysis. Br. J. Ophthalmol. 103, 442-451. doi: 10.1136/ bjophthalmol-2018-312691

McGeachy, M. J., Cua, D. J., and Gaffen, S. L. (2019). The IL-17 family of cytokines in health and disease. Immunity 50, 892-906. doi: 10.1016/j.immuni.2019. 03.021

Mead, B., Amaral, J., and Tomarev, S. (2018). Mesenchymal stem cell-derived small extracellular vesicles promote neuroprotection in rodent models of glaucoma. Invest. Ophthalmol. Vis. Sci. 59, 702-714. doi: 10.1167/iovs.17-22855

Mead, B., and Tomarev, S. (2017). Bone marrow-derived mesenchymal stem cellsderived exosomes promote survival of retinal ganglion cells through miRNAdependent mechanisms. Stem Cells Transl. Med. 6, 1273-1285. doi: 10.1002/ sctm.16-0428

Mocan, M. C., Kadayifcilar, S., and Eldem, B. (2006). Elevated intravitreal interleukin-6 levels in patients with proliferative diabetic retinopathy. Can. J. Ophthalmol. 41, 747-752. doi: 10.3129/i06-070

Mohammed, A., Okwor, I., Shan, L., Onyilagha, C., Uzonna, J. E., and Gounni, A. S. (2020). Semaphorin $3 \mathrm{E}$ regulates the response of macrophages to lipopolysaccharide-induced systemic inflammation. J. Immunol. 204, 128-136. doi: 10.4049/jimmunol.1801514

Moisseiev, E., Anderson, J. D., Oltjen, S., Goswami, M., Zawadzki, R. J., Nolta, J. A., et al. (2017). Protective effect of intravitreal administration of exosomes derived from mesenchymal stem cells on retinal ischemia. Curr. Eye Res. 42, 1358-1367. doi: 10.1080/02713683.2017.1319491

Mora, J. S., Waite, C., Gilbert, C. E., Breidenstein, B., and Sloper, J. J. (2018). A worldwide survey of retinopathy of prematurity screening. Br. J. Ophthalmol. 102, 9-13. doi: 10.1136/bjophthalmol-2017-310709

Movassagh, H., Koussih, L., Shan, L., and Gounni, A. S. (2019). The regulatory role of semaphorin 3E in allergic asthma. Int. J. Biochem. Cell Biol. 106, 68-73. doi: 10.1016/j.biocel.2018.11.006

Movassagh, H., Shan, L., Duke-Cohan, J. S., Chakir, J., Halayko, A. J., Koussih, L., et al. (2017a). Downregulation of semaphorin 3E promotes hallmarks of experimental chronic allergic asthma. Oncotarget 8, 98953-98963. doi: 10. 18632/oncotarget.22144

Movassagh, H., Shan, L., Mohammed, A., Halayko, A. J., and Gounni, A. S. (2017b). Semaphorin 3E deficiency exacerbates airway inflammation. J. Immunol. 198:1805. doi: 10.4049/jimmunol.1601514

Nassiri, S. M., and Rahbarghazi, R. (2013). Interactions of mesenchymal stem cells with endothelial cells. Stem Cells Dev. 23, 319-332. doi: 10.1089/scd.2013.0419

Neufeld, G., Mumblat, Y., Smolkin, T., Toledano, S., Nir-Zvi, I., Ziv, K., et al. (2016). The semaphorins and their receptors as modulators of tumor progression. Drug Resist. Updat. 29, 1-12. doi: 10.1016/j.drup.2016.08.001

Ochsenbein, A. M., Karaman, S., Proulx, S. T., Berchtold, M., Jurisic, G., Stoeckli, E. T., et al. (2016). Endothelial cell-derived semaphorin 3A inhibits filopodia formation by blood vascular tip cells. Development 143, 589-594. doi: 10.1242/ dev. 127670

Oh, W. J., and Gu, C. (2013). The role and mechanism-of-action of Sema3E and Plexin-D1 in vascular and neural development. Semin. Cell Dev. Biol. 24, 156-162. doi: 10.1016/j.semcdb.2012.12.001

Pan, D., Chang, X., Xu, M., Zhang, M., Zhang, S., Wang, Y., et al. (2019). UMSCderived exosomes promote retinal ganglion cells survival in a rat model of optic nerve crush. J. Chem. Neuroanat. 96, 134-139. doi: 10.1016/j.jchemneu.2019. 01.006

Pankajakshan, D., and Agrawal, D. K. (2014). Mesenchymal stem cell paracrine factors in vascular repair and regeneration. J. Biomed. Technol. Res. 1:10. doi: 10.19104/jbtr.2014.107

Park, J., Jeong, S., Park, K., Yang, K., and Shin, S. (2018). Expression profile of microRNAs following bone marrow-derived mesenchymal stem cell treatment in lipopolysaccharide-induced acute lung injury. Exp. Ther. Med. 15, 54955502.

Pokrovskaya, L. A., Zubareva, E. V., Nadezhdin, S. V., Lysenko, A. S., and Litovkina, T. L. (2020). Biological activity of mesenchymal stem cells secretome 
as a basis for cell-free therapeutic approach. Res. Results Pharmacol. 6, 57-68. doi: 10.3897/rrpharmacology.6.49413

Qian, X., An, N., Ren, Y., Yang, C., Zhang, X., and Li, L. (2020). Immunosuppressive effects of mesenchymal stem cells-derived exosomes. Stem Cell Rev. Rep. doi: 10.1007/s12015-020-10040-7 [Epub ahead of print].

Rani, S., Ryan, A. E., Griffin, M. D., and Ritter, T. (2015). Mesenchymal stem cellderived extracellular vesicles: toward cell-free therapeutic applications. Mol. Ther. 23, 812-823. doi: 10.1038/mt.2015.44

Rivera, J. C., Dabouz, R., Noueihed, B., Omri, S., Tahiri, H., and Chemtob, S. (2017a). Ischemic retinopathies: oxidative stress and inflammation. Oxid. Med. Cell. Longev. 2017:3940241.

Rivera, J. C., Noueihed, B., Madaan, A., Lahaie, I., Pan, J., Belik, J., et al. (2017b). Tetrahydrobiopterin (BH4) deficiency is associated with augmented inflammation and microvascular degeneration in the retina. J. Neuroinflamm. 14:181.

Rivera, J. C., Sitaras, N., Noueihed, B., Hamel, D., Madaan, A., Zhou, T., et al. (2013). Microglia and interleukin-lbeta in ischemic retinopathy elicit microvascular degeneration through neuronal semaphorin-3A. Arterioscler. Thromb. Vasc. Biol. 33, 1881-1891. doi: 10.1161/atvbaha.113. 301331

Sabanayagam, C., Banu, R., Chee, M. L., Lee, R., Wang, Y. X., Tan, G., et al. (2019). Incidence and progression of diabetic retinopathy: a systematic review. Lancet Diabetes Endocrinol. 7, 140-149.

Sakurai, A., Gavard, J., Annas-Linhares, Y., Basile, J. R., Amornphimoltham, P., Palmby, T. R., et al. (2010). Semaphorin 3E initiates antiangiogenic signaling through Plexin D1 by regulating Arf6 and R-Ras. Mol. Cell Biol. 30, 3086-3098. doi: 10.1128/mcb.01652-09

Semeran, K., Pawlowski, P., Lisowski, L., Szczepaniak, I., Wojtowicz, J., Lawicki, S., et al. (2013). Plasma levels of IL-17, VEGF, and adrenomedullin and S-cone dysfunction of the retina in children and adolescents without signs of retinopathy and with varied duration of diabetes. Mediators Inflamm. 2013:274726.

Seyedrazizadeh, S. Z., Poosti, S., Nazari, A., Alikhani, M., Shekari, F., Pakdel, F., et al. (2020). Extracellular vesicles derived from human ES-MSCs protect retinal ganglion cells and preserve retinal function in a rodent model of optic nerve injury. Stem Cell Res. Ther. 11:203.

Shao, Z., Friedlander, M., Hurst, C. G., Cui, Z., Pei, D. T., Evans, L. P., et al. (2013). Choroid sprouting assay: an ex vivo model of microvascular angiogenesis. PLoS One 8:e69552. doi: 10.1371/journal.pone.0069552

Shapoori, S., Ganjalikhani-Hakemi, M., Rezaeepoor, M., Alsahebfosoul, F., Khosravi, S., Etemadifar, M., et al. (2019). Negative regulation of semaphorin$3 \mathrm{~A}$ expression in peripheral blood mononuclear cells using MicroRNA-497-5p. Iran. J. Med. Sci. 44, 325-333.

Sharma, A., Levaillant, C. J., Plant, G. W., and Harvey, A. R. (2014). Changes in expression of Class 3 Semaphorins and their receptors during development of the rat retina and superior colliculus. BMC Dev. Biol. 14:34. doi: 10.1186/ s12861-014-0034-9

Shimizu, I., Yoshida, Y., Moriya, J., Nojima, A., Uemura, A., Kobayashi, Y., et al. (2013). Semaphorin3E-induced inflammation contributes to insulin resistance in dietary obesity. Cell Metab. 18, 491-504. doi: 10.1016/j.cmet.2013. 09.001

Sierra, J. R., Corso, S., Caione, L., Cepero, V., Conrotto, P., Cignetti, A., et al. (2008). Tumor angiogenesis and progression are enhanced by Sema4D produced by tumor-associated macrophages. J. Exp. Med. 205, 1673-1685. doi: 10.1084/jem. 20072602

Singer, N. G., and Caplan, A. I. (2011). Mesenchymal stem cells: mechanisms of inflammation. Annu. Rev. Pathol. 6, 457-478. doi: 10.1146/annurev-pathol011110-130230

Sitaras, N., Rivera, J. C., Noueihed, B., Bien-Aime, M., Zaniolo, K., Omri, S., et al. (2015). Retinal neurons curb inflammation and enhance revascularization in ischemic retinopathies via proteinase-activated receptor-2. Am. J. Pathol. 185, 581-595. doi: 10.1016/j.ajpath.2014.10.020

Sivan, P. P., Syed, S., Mok, P. L., Higuchi, A., Murugan, K., Alarfaj, A. A., et al. (2016). Stem cell therapy for treatment of ocular disorders. Stem Cells Int. 2016:8304879.

Smith, L. E., Wesolowski, E., Mclellan, A., Kostyk, S. K., D’amato, R., Sullivan, R., et al. (1994). Oxygen-induced retinopathy in the mouse. Invest. Ophthalmol. Vis. Sci. 35, 101-111.
Solt, L. A., and Burris, T. P. (2012). Action of RORs and their ligands in (patho)physiology. Trends Endocrinol. Metab. 23, 619-627. doi: 10.1016/j.tem. 2012.05.012

Sood, B. G., Madan, A., Saha, S., Schendel, D., Thorsen, P., Skogstrand, K., et al. (2010). Perinatal systemic inflammatory response syndrome and retinopathy of prematurity. Pediatr. Res. 67, 394-400. doi: 10.1203/pdr.0b013e3181d $01 \mathrm{a} 36$

Spees, J. L., Lee, R. H., and Gregory, C. A. (2016). Mechanisms of mesenchymal stem/stromal cell function. Stem Cell Res. Ther. 7:125.

Stahl, A., Connor, K. M., Sapieha, P., Chen, J., Dennison, R. J., Krah, N. M., et al. (2010). The mouse retina as an angiogenesis model. Invest. Ophthalmol. Vis. Sci. $51,2813-2826$.

Stahl, A., Connor, K. M., Sapieha, P., Willett, K. L., Krah, N. M., Dennison, R. J., et al. (2009). Computer-aided quantification of retinal neovascularization. Angiogenesis 12, 297-301. doi: 10.1007/s10456-009-9155-3

Suda, K., Guo, C., Oishi, A., Ikeda, S., Uemura, A., and Yoshimura, N. (2014). Therapeutic potential of semaphorin $3 \mathrm{E}$ for the treatment of choroidal neovascularization. Invest. Ophthalmol. Vis. Sci. 55, 4700-4706. doi: 10.1167/ iovs.14-14087

Sun, Y., Liu, C. H., Wang, Z., Meng, S. S., Burnim, S. B., Sangiovanni, J. P., et al. (2017). RORalpha modulates semaphorin $3 \mathrm{E}$ transcription and neurovascular interaction in pathological retinal angiogenesis. FASEB J. 31, 4492-4502. doi: 10.1096/fj.201700172r

Sun, Y., Ma, J., Li, D., Li, P., Zhou, X., Li, Y., et al. (2019). Interleukin-10 inhibits interleukin-1beta production and inflammasome activation of microglia in epileptic seizures. J. Neuroinflamm. 16:66.

Talia, D. M., Deliyanti, D., Agrotis, A., and Wilkinson-Berka, J. L. (2016). Inhibition of the nuclear receptor RORgamma and interleukin-17A suppresses neovascular retinopathy: involvement of immunocompetent microglia. Arterioscler. Thromb. Vasc. Biol. 36, 1186-1196. doi: 10.1161/atvbaha.115.307080

Tao, H., Han, Z., Han, Z. C., and Li, Z. (2016). Proangiogenic features of mesenchymal stem cells and their therapeutic applications. Stem Cells Int. 2016, 1314709-1314709.

Timmers, L., Lim, S. K., Hoefer, I. E., Arslan, F., Lai, R. C., Van Oorschot, A. A., et al. (2011). Human mesenchymal stem cell-conditioned medium improves cardiac function following myocardial infarction. Stem Cell Res. 6, 206-214. doi: 10.1016/j.scr.2011.01.001

Toledano, S., Nir-Zvi, I., Engelman, R., Kessler, O., and Neufeld, G. (2019). Class-3 semaphorins and their receptors: potent multifunctional modulators of tumor progression. Int. J. Mol. Sci. 20:556. doi: 10.3390/ijms20030556

Tran, C., and Damaser, M. S. (2015). Stem cells as drug delivery methods: application of stem cell secretome for regeneration. Adv. Drug Deliv. Rev. 82-83, 1-11. doi: 10.1016/j.addr.2014.10.007

Uemura, R., Xu, M., Ahmad, N., and Ashraf, M. (2006). Bone marrow stem cells prevent left ventricular remodeling of ischemic heart through paracrine signaling. Circ. Res. 98, 1414-1421. doi: 10.1161/01.res.0000225952.61196.39

Usategui-Martin, R., Puertas-Neyra, K., Garcia-Gutierrez, M. T., Fuentes, M., Pastor, J. C., and Fernandez-Bueno, I. (2020). Human mesenchymal stem cell secretome exhibits a neuroprotective effect over in vitro retinal photoreceptor degeneration. Mol. Ther. Methods Clin. Dev. 17, 1155-1166. doi: 10.1016/j. omtm.2020.05.003

Wang, J., Ren, H., Yuan, X., Ma, H., Shi, X., and Ding, Y. (2018). Interleukin10 secreted by mesenchymal stem cells attenuates acute liver failure through inhibiting pyroptosis. Hepatol. Res. 48, E194-E202.

Wanschel, A., Seibert, T., Hewing, B., Ramkhelawon, B., Ray, T. D., Van Gils, J. M., et al. (2013). Neuroimmune guidance cue Semaphorin 3E is expressed in atherosclerotic plaques and regulates macrophage retention. Arterioscler. Thromb. Vasc. Biol. 33, 886-893. doi: 10.1161/atvbaha.112. 300941

Weiss, A. R. R., and Dahlke, M. H. (2019). Immunomodulation by mesenchymal stem cells (MSCs): mechanisms of action of living, apoptotic, and dead MSCs. Front. Immunol. 10:1191. doi: 10.3389/fimmu.2019.01191

$\mathrm{Xu}$, S., and Cao, X. (2010). Interleukin-17 and its expanding biological functions. Cell. Mol. Immunol. 7, 164-174. doi: 10.1038/cmi. 2010.21

Yang, W. J., Hu, J., Uemura, A., Tetzlaff, F., Augustin, H. G., and Fischer, A. (2015). Semaphorin-3C signals through Neuropilin-1 and PlexinD1 receptors 
to inhibit pathological angiogenesis. EMBO Mol. Med. 7, 1267-1284. doi: 10.15252/emmm.201404922

Yu, B., Shao, H., Su, C., Jiang, Y., Chen, X., Bai, L., et al. (2016). Exosomes derived from MSCs ameliorate retinal laser injury partially by inhibition of MCP-1. Sci. Rep. 6:34562.

Yusop, N., Battersby, P., Alraies, A., Sloan, A. J., Moseley, R., and Waddington, R. J. (2018). Isolation and characterisation of mesenchymal stem cells from rat bone marrow and the endosteal niche: a comparative study. Stem Cells Int. 2018:6869128.

Zhang, L., Dong, Z. F., and Zhang, J. Y. (2020). Immunomodulatory role of mesenchymal stem cells in Alzheimer's disease. Life Sci. 246:117405. doi: 10. 1016/j.lfs.2020.117405

Zhu, H., Guo, Z.-K., Jiang, X.-X., Li, H., Wang, X.-Y., Yao, H.-Y., et al. (2010). A protocol for isolation and culture of mesenchymal stem cells from mouse compact bone. Nat. Protoc. 5:550. doi: 10.1038/nprot.20 09.238

Conflict of Interest: The authors declare that the research was conducted in the absence of any commercial or financial relationships that could be construed as a potential conflict of interest.

Copyright (c) 2021 Noueihed, Rivera, Dabouz, Abram, Omri, Lahaie and Chemtob. This is an open-access article distributed under the terms of the Creative Commons Attribution License (CC BY). The use, distribution or reproduction in other forums is permitted, provided the original author(s) and the copyright owner(s) are credited and that the original publication in this journal is cited, in accordance with accepted academic practice. No use, distribution or reproduction is permitted which does not comply with these terms. 